\title{
Comparison of the Effectiveness of Schema Therapy and Integrated Cognitive-Speech Approach in Emotional Regulation, and Distress Tolerance of Individuals Suffering from Stuttering
}

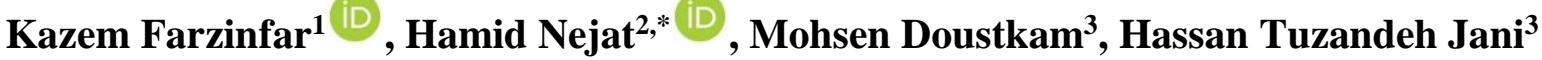 \\ ${ }^{1}$ PhD Student, Department of Psychology, Neyshabour Branch, Islamic Azad University, Neyshabour, Iran \\ 2 Assistant Professor, Department of Psychology, Quchan Branch, Islamic Azad University, Quchan, Iran \\ ${ }_{3}^{3}$ Assistant Professor, Department of Psychology, Neyshabour Branch, Islamic Azad University, Neyshabour, Iran \\ ${ }^{4}$ Associate Professor, Department of Psychology, Neyshabour Branch, Islamic Azad University, Neyshabour, Iran \\ * Corresponding Author: Hami Nejat, Department of Psychology, Quchan Branch, Islamic Azad University, Quchan, Iran. \\ Email:Hnejat54@yahoo.com
}

Received: 03.10 .2020

Accepted: 28.01 .2021

\section{How to Cite this Article:}

Farzinfar K, Nejat H, Doustkam M, Tuzandeh Jani H. Comparison of the Effectiveness of Schema Therapy and Integrated Cognitive-Speech Approach in Emotional Regulation, and Distress Tolerance of Individuals Suffering from Stuttering. Avicenna J Clin Med. 2021; 27(4): 239-252. DOI: $10.29252 /$ ajcm.27.4.239

\section{Abstract}

Background and Objective: Numerous approaches, including schema therapy, and an integrated cognitive-speech approach, have been suggested to reduce emotions and increase distress tolerance in people with stuttering. The present study aimed to make a comparison between the effectiveness of schema therapy and integrated cognitive-speech approach in emotional regulation and distress tolerance of individuals suffering from stuttering.

Materials and Methods: This quasi-experimental study was conducted based on a pre-test, post-test design, and a follow-up test with a control group. The statistical population included all individuals aged 18-30 who suffered from stuttering in Sabzevar city. The sample consisted of 30 people who were selected via convenience sampling and were randomly assigned to two experimental groups and one control group ( $\mathrm{n}=10$ in each group). The experimental schema therapy group underwent treatment in 12 90-minute sessions, the integrated cognitive-speech approach group received 12 60minute sessions of treatment, and the control group received no treatments. The instruments of the research were Gross and John (2003) Emotional Regulation Questionnaire, and Simons and Gaher (2005) Distress Tolerance Questionnaire. These instruments were conducted on three groups in all phases of pre-testing and post-testing and follow-up. The one-way repeated measures ANOVA and Tukey post hoc test were used to analyze the data. Results: As evidenced by the obtained results, the schema therapy and integrated cognitive-speech approach had a significant effect on emotional regulation and distress tolerance of individuals suffering from stuttering $(\mathrm{P}<0.05)$.

Conclusion: The results of the present study indicated that none of the treatments outperformed the other ones; nonetheless, the integrated cognitive-speech approach was more effective in distress tolerance index.

Keywords: Distress Tolerance, Emotional Regulation, Integrated Cognitivespeech Approach, Schema Therapy, Stuttering 
dof: $10.29252 /$ ajcm.27.4.239

\title{
مقايسه اثربخشى طر حواره درمانى و رويكر د تلفيقى شناختى_كفتارى بر تنظيم هيجانى و تحمل يريشانى افر اد مبتلابه لكنت
}

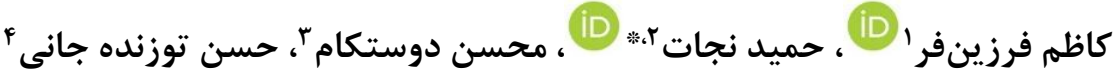 \\ ' دانشجوى دوره دكترى، گروه روانشناسى، واحد نيشابور، دانشعاه آزاد اسلامى، نيشابور، ايران

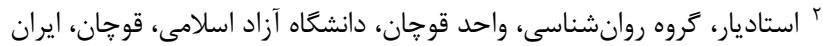

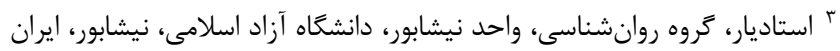

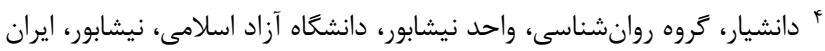

Hnejat54@yahoo.com : نويسنده مسئول: حميد نجات، گروه روانشناسى، واحد قوجان، دانشعاه آزاد اسلامى، قوجان، ايران. ايميل

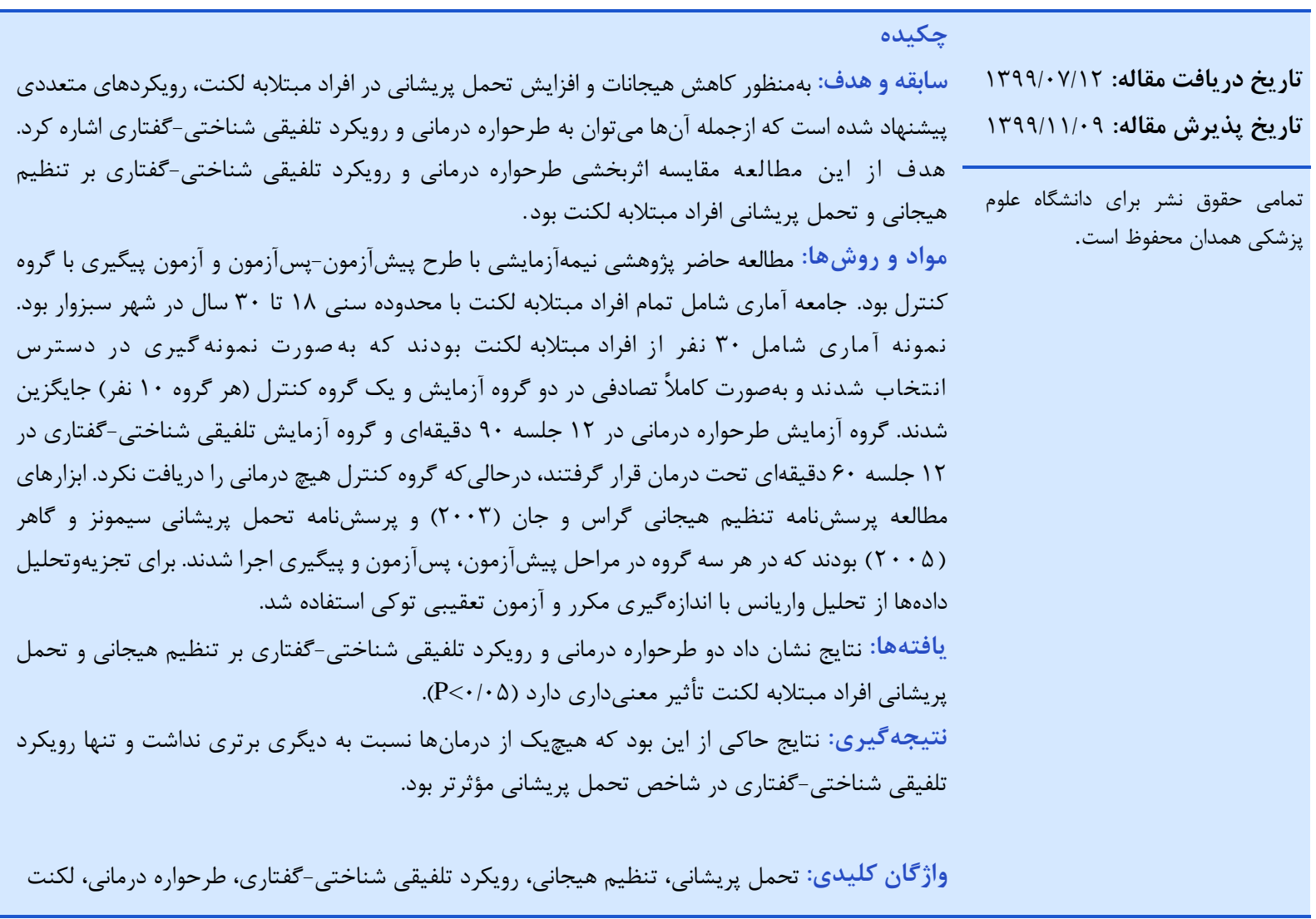

جشم و تغييرات قلبى-عروقى همراه است [r]. تحقيقات

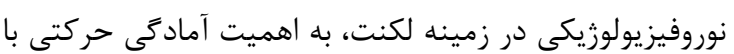

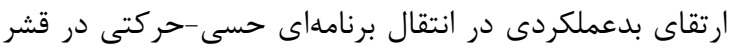

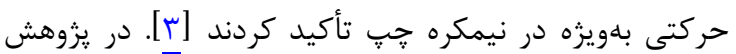

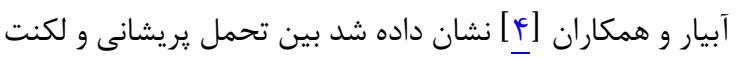

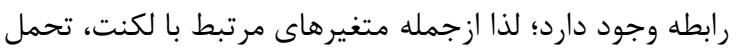
يريشانى است. تحمل يريشانى از سازهاى معمول براى يروهش در زمينه
لكنت نوعى اختلال روانى كَتار رشدى-عصبى است كه علائم آن با قفل و تكرار سيلابها و وعدا و كشيدَّويى صداها

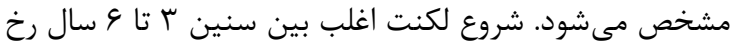

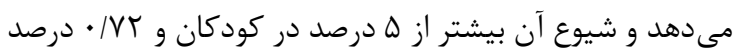

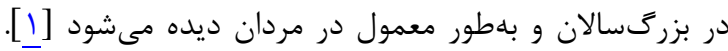

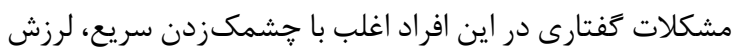
لبها يا فك، تيكهاى صورت، تكانهاى سر، رَرهردن مشتها، سرخشدن صورت، رنت يريدگى، عرق كردن، حركات 
بىثباتى هيجانى و مشكل در تنظيم هيجان در افراد داراى

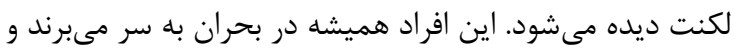

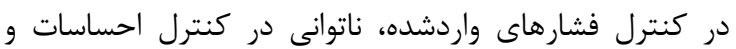

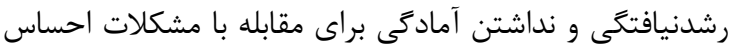

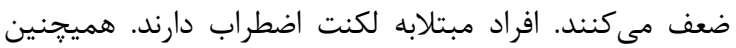
حالتهاى عاطفى منفى در آنها ديده مىشود و به دليل مشكلات

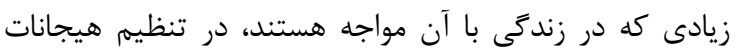

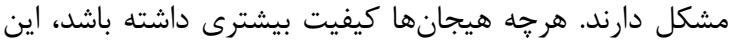

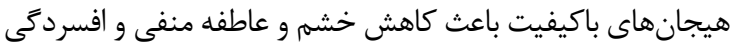

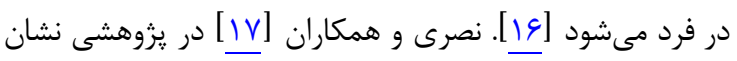

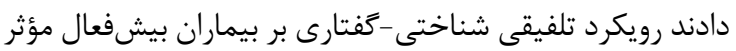
واقع شده است. براى كاهش هيجانات و افزايش تحمل يريشانى در افراد مبتلابه لكنت رويكردهاى متعددى بيشنهاد شده است كه ازجمله

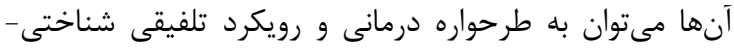

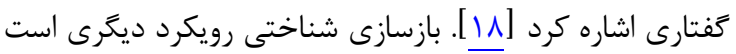
كه برخى اوقات، نتاه متفاوتى به ويزگ

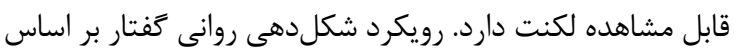
شرطىسازى فعال براى رفع يا كاهش علائم قابل مشاهده لكنت، مانى

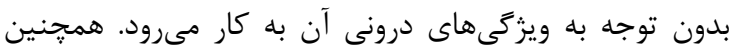

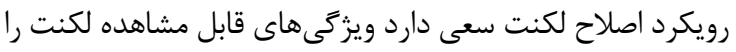

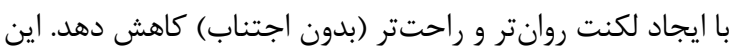

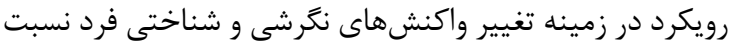

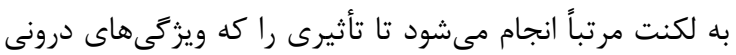

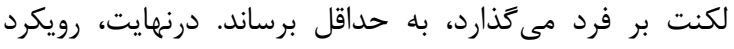

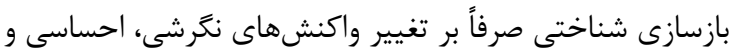
شناختى فرد نسبت به لكنت متمركز مى شود تا تأثير عوارض و

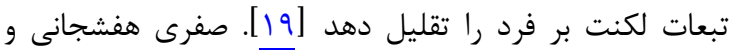
خرمشاهى در يزوهشى با عنوان لادرمانهاى مؤثر (رويكرد تلفيقى دهي

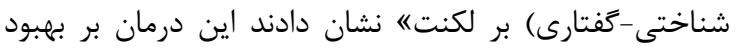
لكنت مؤثر است [r] [ب]

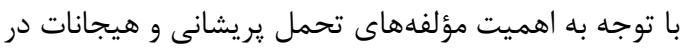

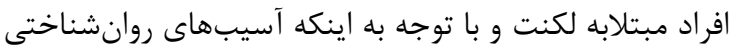

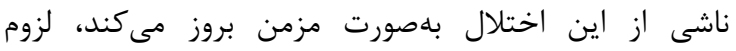

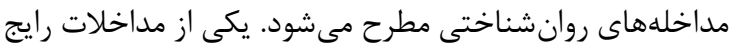

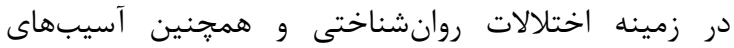

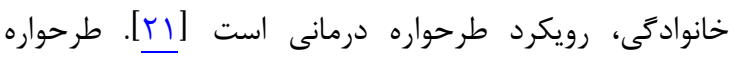

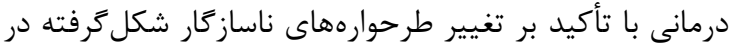

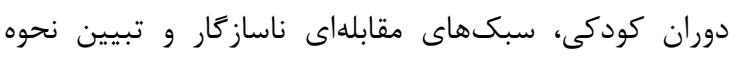

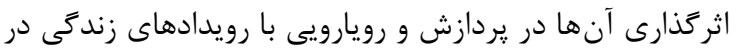

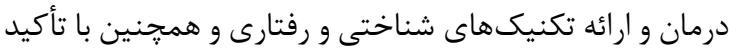

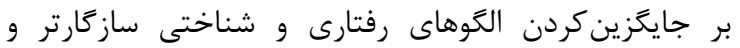

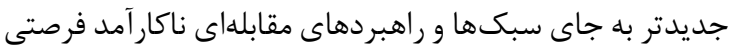

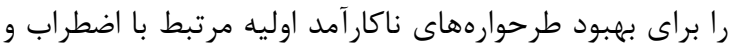

بـىنظمى عاطفى است. به توانايى فرد در تجربه و تحمل حالات

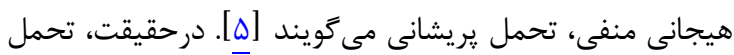

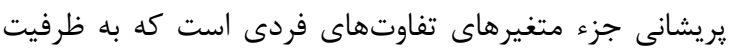

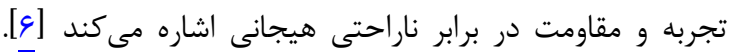

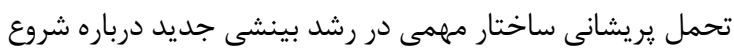

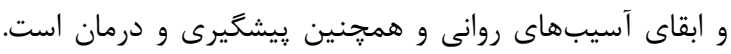

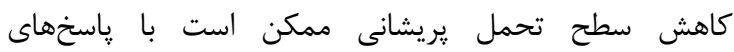

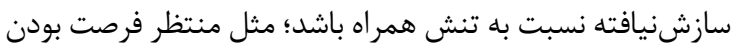

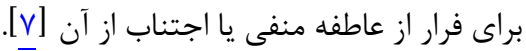

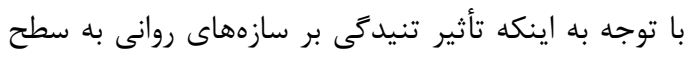

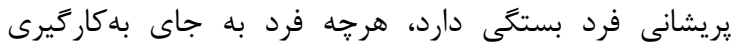

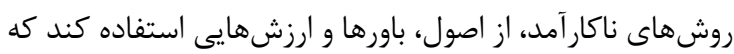

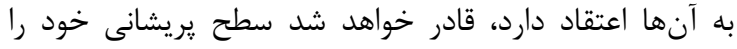

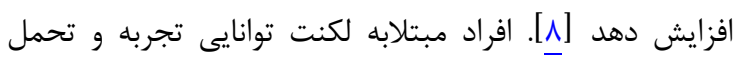
حالات هيجانى منفى را ندارند. درحقيقت، ظرفيت دائ تجربه

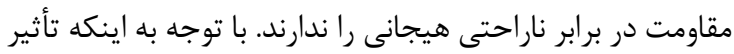

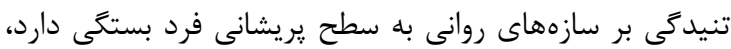

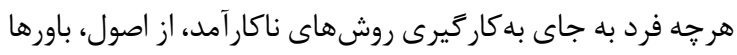

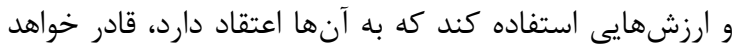

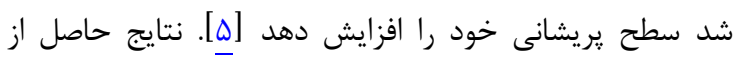
يزوهش Ntourou و همكاران [9] حاكى از آن بود كه كودكان داراى لكنت زبان، واكنشهاى عاطفى منفى بيشترى نسبت به به إنه كود كان بدون لكنت زبان از خود نشان مى دهند.

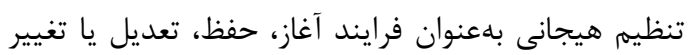

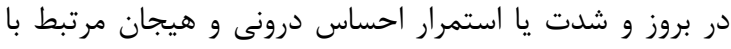

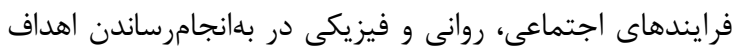

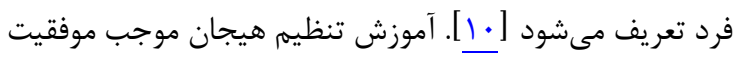

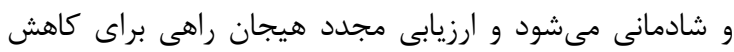

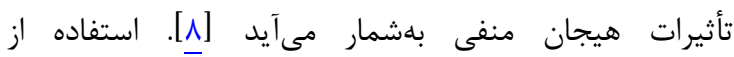
استراتزىهاى مربوط به تنظيم هيجان منجر به افزايش هيجانات مئنات

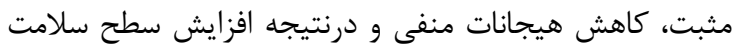
روان افراد مىشود [11]. وجود نقص در تنظيم هيجانى بينفردى باد اخدود الختلالات

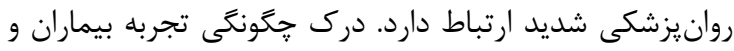

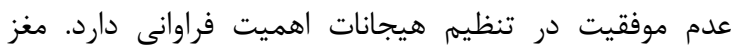
هيجانات را به سوى كرايشهاى فعال سازكار تنظيم مى كند.

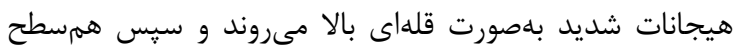

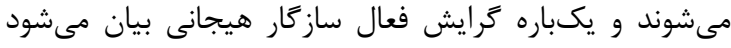

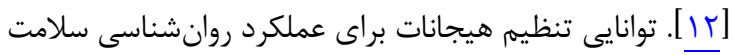

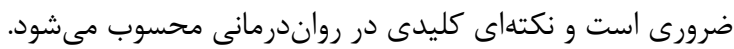

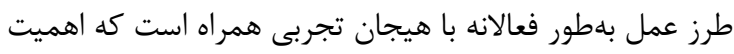

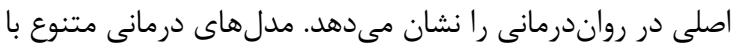

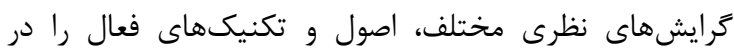

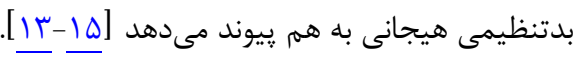


زن و مرد بودند كه در سه ماهه سوم سال وجسا به كلينيكهاى

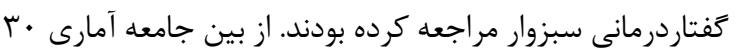

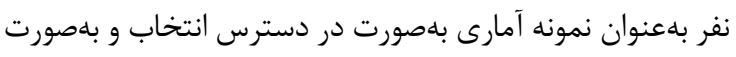

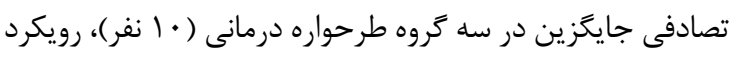

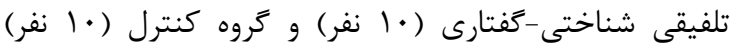
كمارده شدند.

ملاكهاى تعيين حجم نمونه شامل توان آزمون برابر فاء ـ

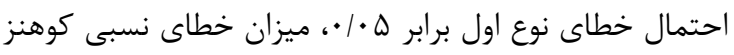

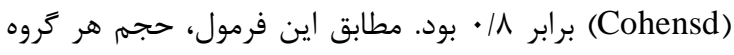

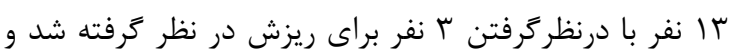

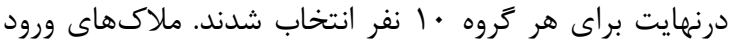

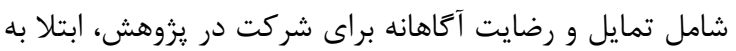

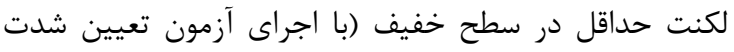

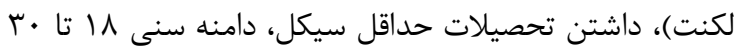

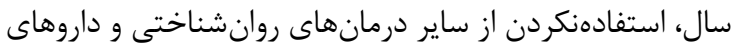

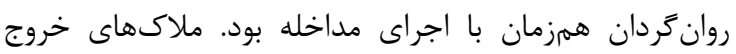

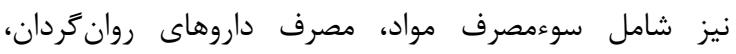

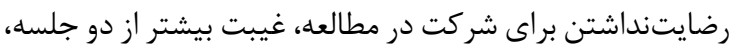

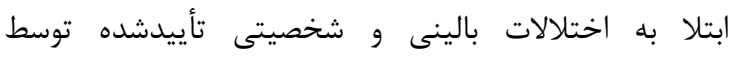

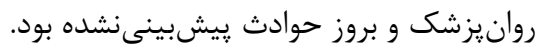

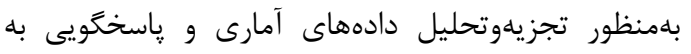

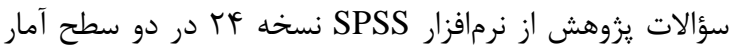

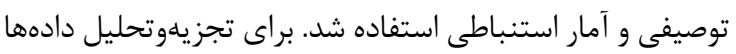

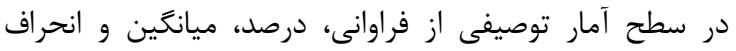

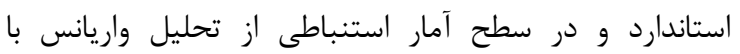
اندازهيرى مكرر و آزمون تعقيبى توكى استفاده شد.

\section{محتواى ז/ جلسه طرحواره درمانى به طور خلاصه}

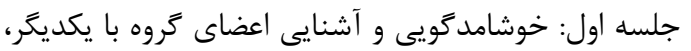

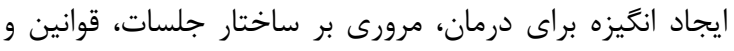

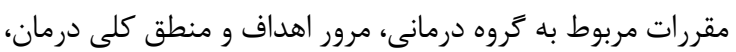
اجراى ييشآزمون.

جلسه دوم: تعريف طرحواره درمانى، طرحوارههاى ناساز

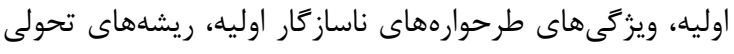
طرحوارهها.

جلسه سوم: معرفى حوزههاى طرحواره و طرحوارههاى ناساز گار اوليه، شرح مختصر بيولوزى طرحوارههاى ناساز حار اوليه، توضيح عملكردهاى طرحواره، شرح مختصر تداوم و بهببود بهر طرحواره.

جلسه جهارم: معرفى سبكها و پِاسخهاى مقابلهاى ناسازگًار

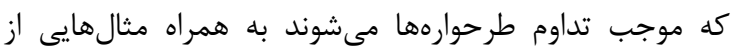
زندگى روزمره، تعريف مفهوم ذهنيتهاى طرحوارهاى، ايجاد

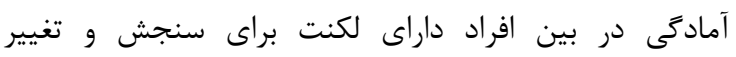
طرحوارهها.
لكنت فراهم مى آورد [بr]. Young و همكاران طرحواره درمانى را براى درمان بيماران

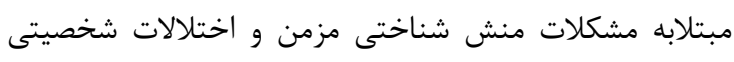

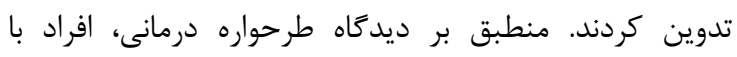

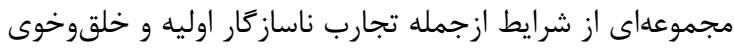

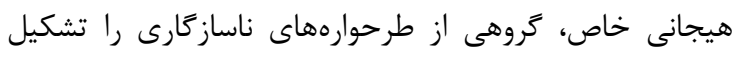

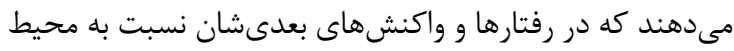

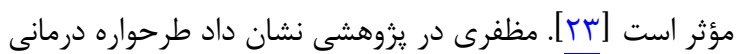

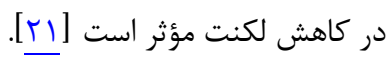
طرحوارهها را مىتوان ساختارهايى براى بازئ إيابى مفاهيم

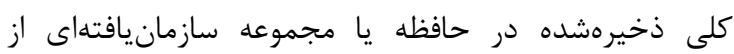

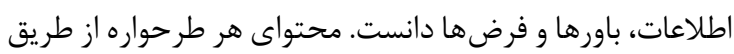

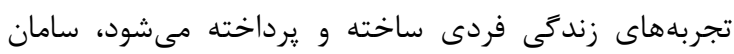

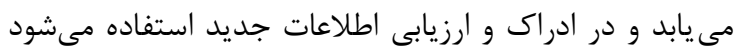

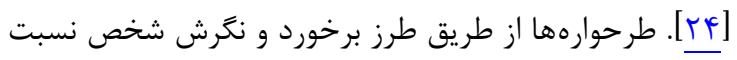

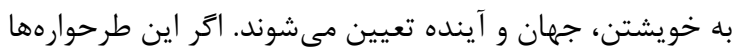

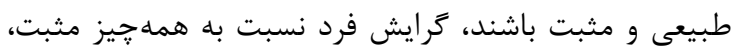

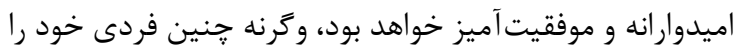

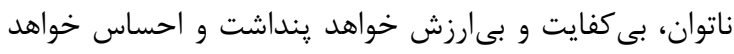

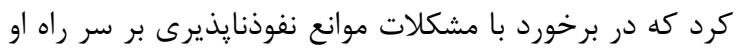

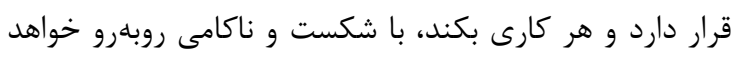

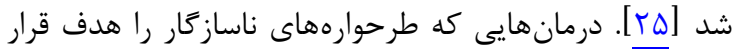

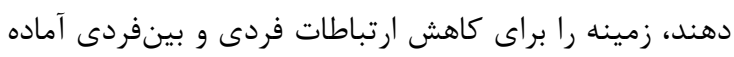

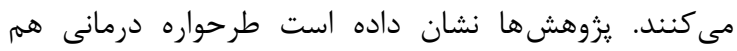

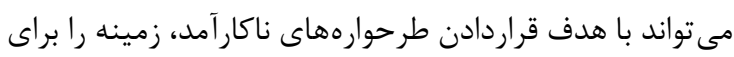

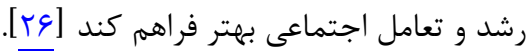

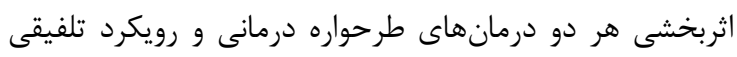

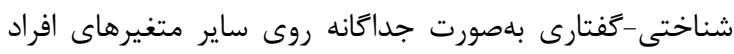

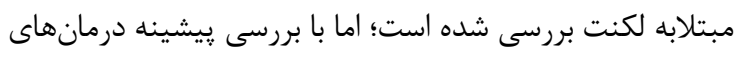

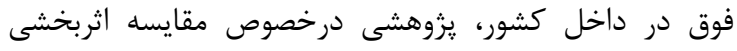

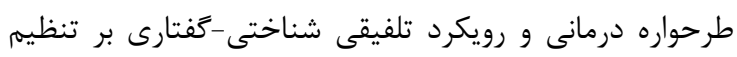

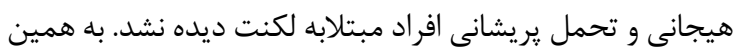

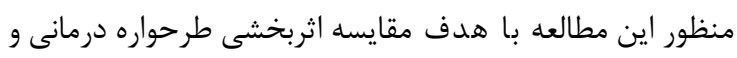

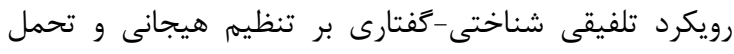

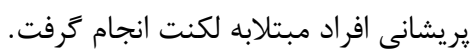

\section{مواد و روشها}

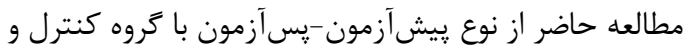

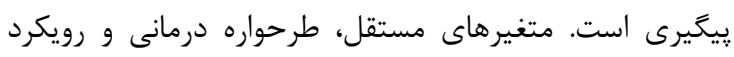

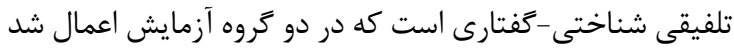

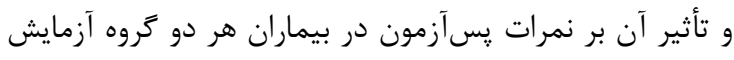

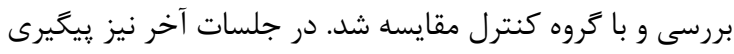

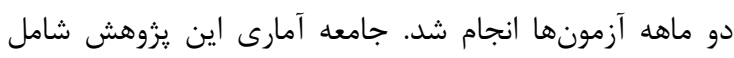

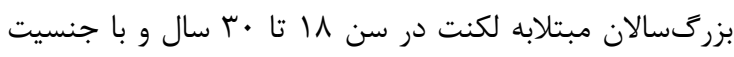


(جملات كوتاه) و كفتار محاورهاى با تأكيد بر استفاده از كفتار كشيده اغراقآميز بر اساس مراحل اوليه برنامه كميردان.

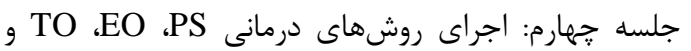
LCC (Light Contact Consonant)

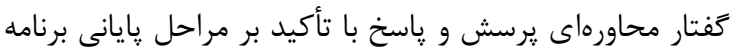
كميردان.

جلسه קֶنجم: تكرار برنامه درمانى جلسه جهارم و اعمال عناصر اوليه روش Desensitization Variation, Approximation, (Stabilization

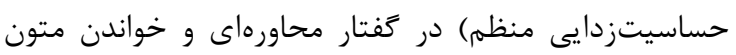
مختلف.

جلسه ششم: انجام برنامه درمانى جلسه ينجم به همراه سه

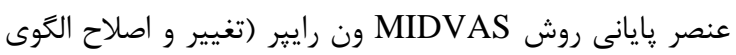

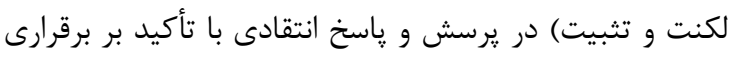

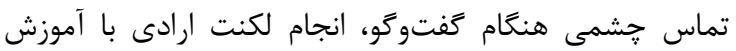
خودكنترلى بر اصلاح لكنت.

جلسه هفتم: انجام برنامه درمانى بازسازى روانى كفتار به

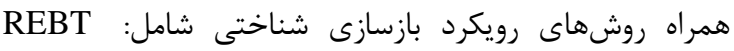
(Rational Emotive Behavioral Therapy), PCT (Personal Construct Therapy), CAN (Constructive Approach Narrative), POWER (Permission, Ownership, Weel-being, Esteem of onself, مبتنى بر راهكارهاى Resilience, Responsibility) توانمندساختن فرد در شناسايى افكار و باورهاى غيرمنطقى خود. جلسه هشتم: اجراى روش تلفيقى شناختى-كفتارى در

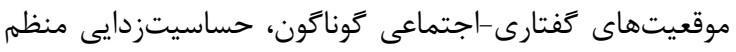
و تصويرسازى ذهنى بلهصورت همزمان و تمرين كَفتو

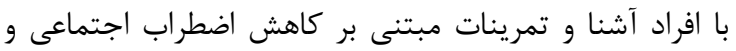

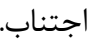

جلسه نهم: اجراى روش تلفيقى شناختى-خفتارى در گفتار

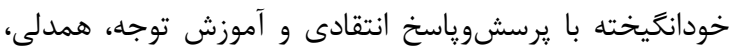

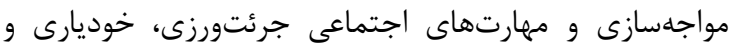
كَفتوَوهاى تلفنى با افراد آشنا و غريبه.

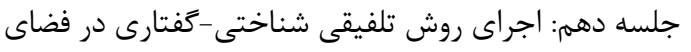

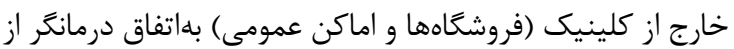

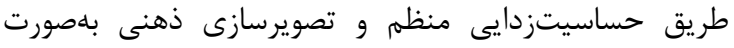

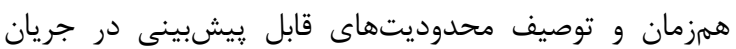
كفتو گو و خواندن شفاهى.

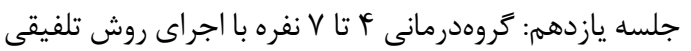

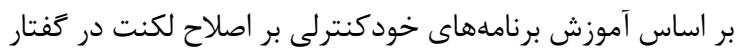

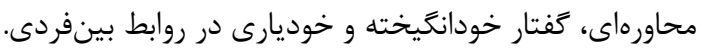

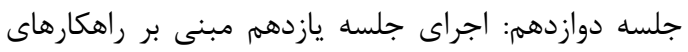
تقويت كَتار طبيعى كنترلشده با نظارت شناختى، ارائه لكنت

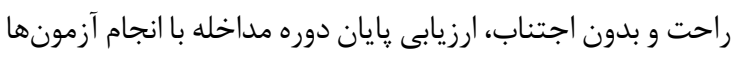

جلسه هنجم: آموزش طرحوارههاى شرطى و غيرشرطى،

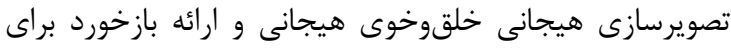
شناسايى بيشتر طرحواره، ايجاد آمادگى براى تغييرير.

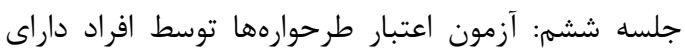

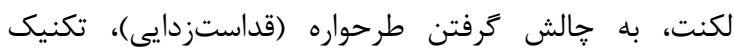
ي يوستارنخرى، نامه معرفى خود. جلسه هفتم: بررسى شواهد تأييدكننده و ردكننده طرحو مواره،

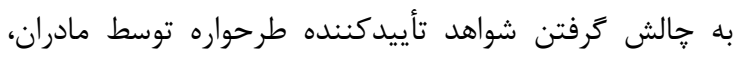

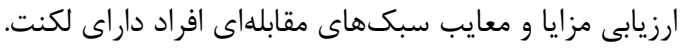
جلسه هشته: برقرارى كفتو طرحواره توسط مادران، تدوين و ساخت كارتهاى برى آموزشى به

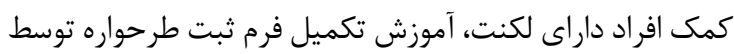

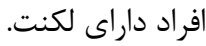
جلسه نهم: ارائه منطق استفاده از اين تكنيكها در درمان،

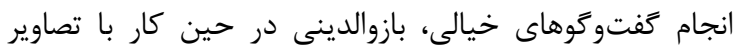

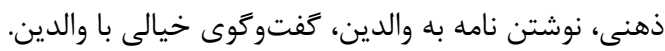

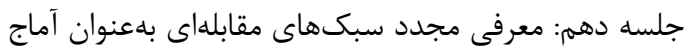

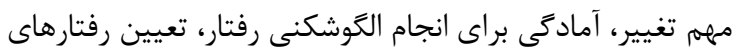

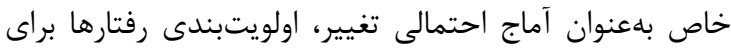

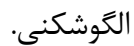
جلسه يازدهم: فهرست كردن مصاديق زّاسخهاى مقابلهاى

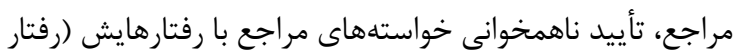

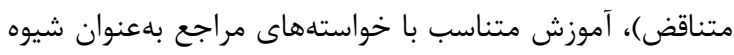
صحيح رسيدن به خواستههايش.

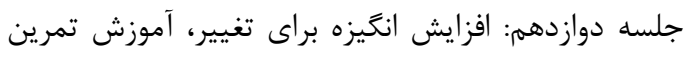

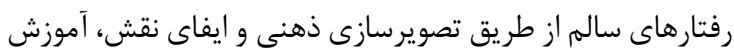

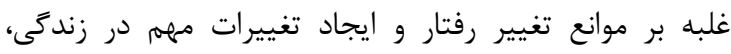

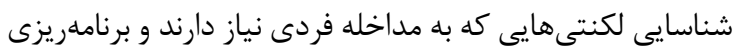

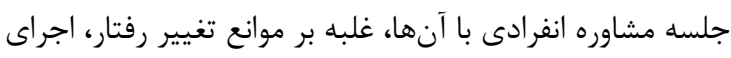

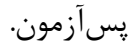

\section{محتواى || جلسه رويكرد تلفيقى شناختى-كفتارى بهطور خلاصه}

جلسه اول: مصاحبه و اجراى آزمون تعيين شدت لكنت در

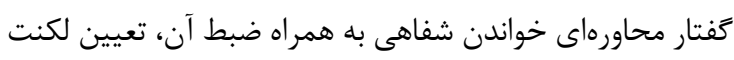

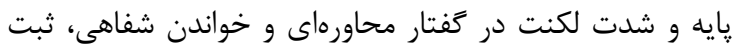

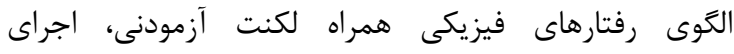

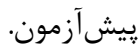
جلسه دوم: اجراى روشهاى درمانى شكلدهیى روانى كفتار همراه با (PS: Prolonged Speech, EO: Easy Onset) خودآكاهى از عملكرد دستخاه كفتار و سازوكار تنفس در كفتار شفاهى و خواندن كلمات و عبارات ساده.

جلسه سوم: اجراى روشهاى درمانى PS PO EO حين خواندن متون فارسى و كفتار شفاهى (Time-Out) 


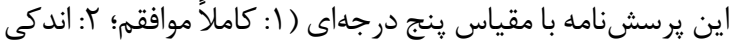

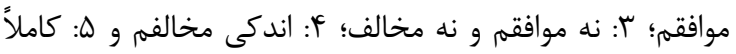

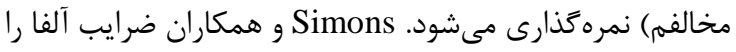

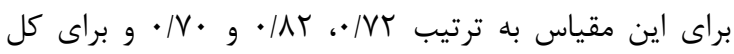

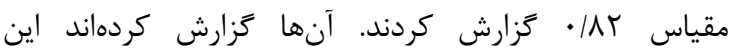

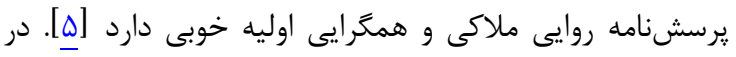

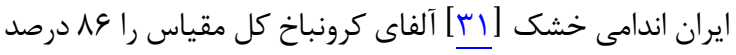

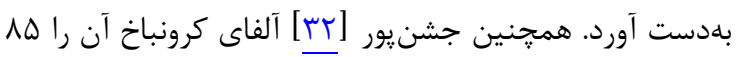
درصد كَارش كرده است.

\section{يافته ها}

نتايج نشان مىدهد \1 نفر (•9 درصد) از آزمودنىها زن بودند كه بيشترين افراد را به خود اختصاص داده است. به ترتيب

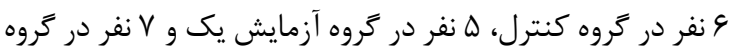

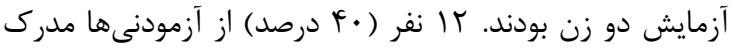

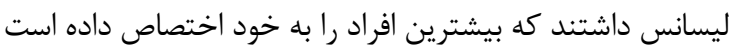

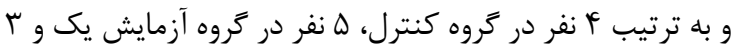

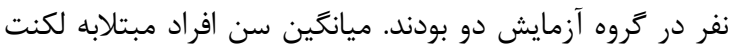

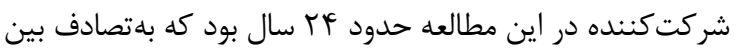

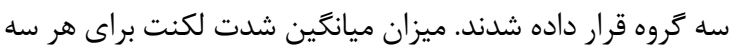

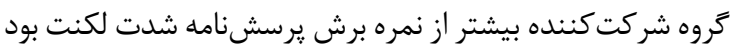

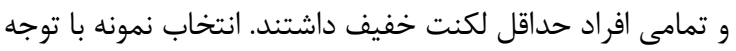

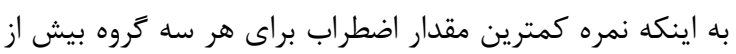

$$
\text { 11 بود، بلهدرستى انجام شده است. }
$$

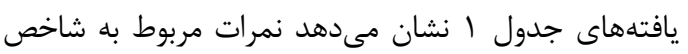

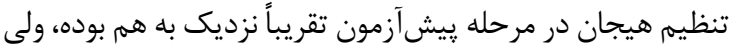

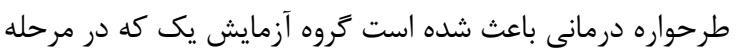

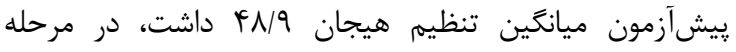

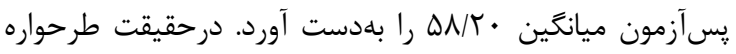

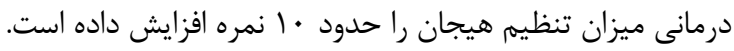

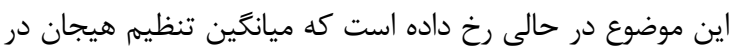

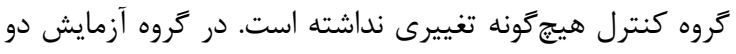

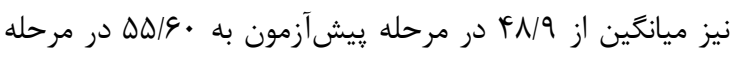

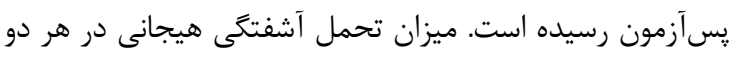

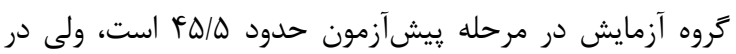

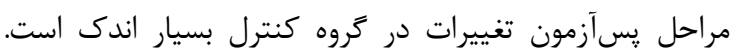

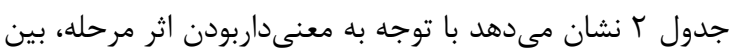

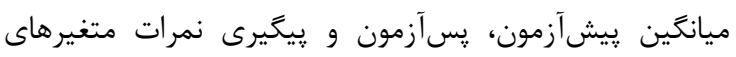

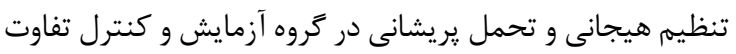

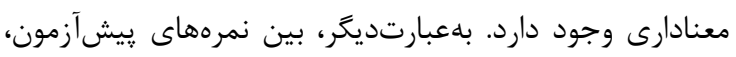

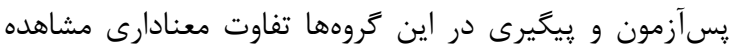

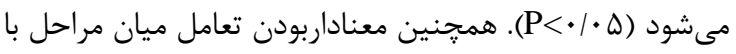

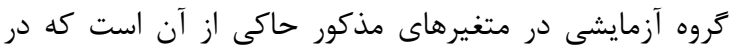

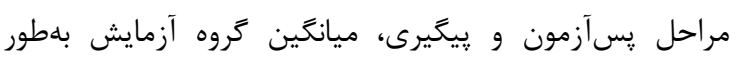

در كفتار محاورهاى و خواندن شفاهى بلصورت جلسات فردى و

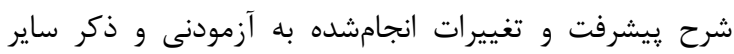
توصيdهاى درمانى، اجراى يسآزمون.

\section{ابزارهاى استفادهشده براى جمعآورى دادهها}

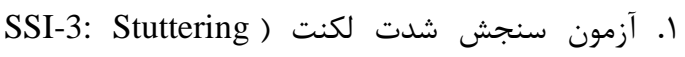

Severity Instrument-3

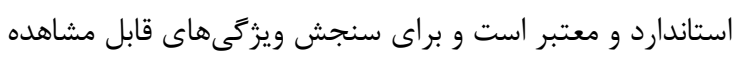

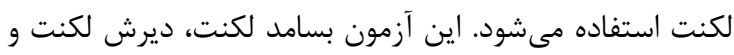

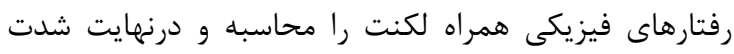

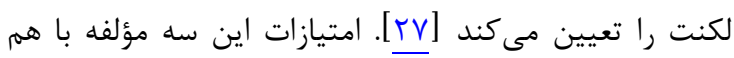
جمع مىشوند و شدت لكنت فرد در ينج درجه خيلى خفيف

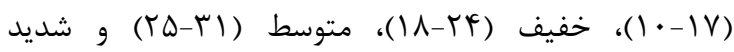

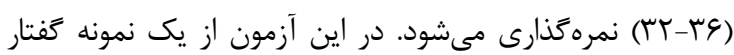

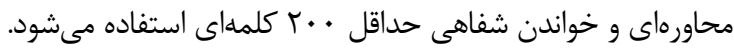

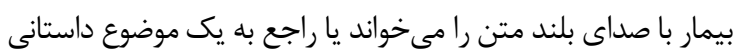

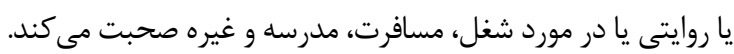

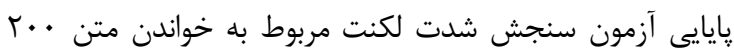

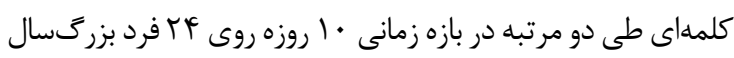

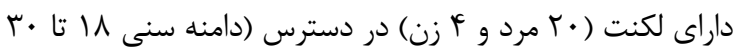

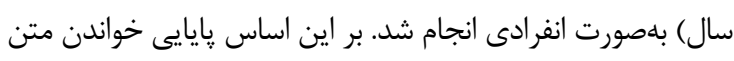

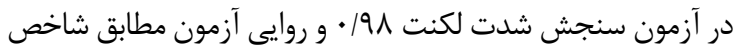

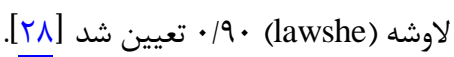

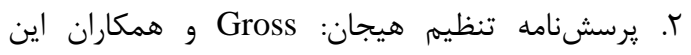

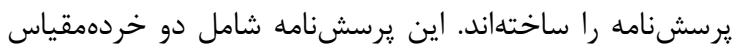

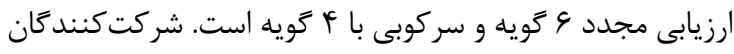

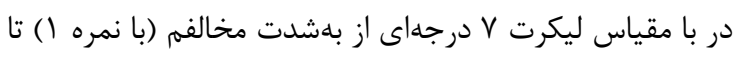

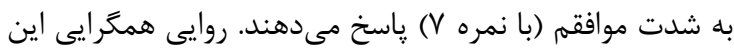

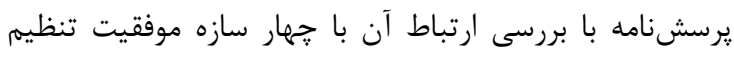

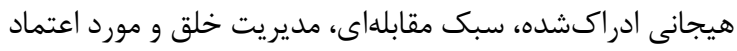

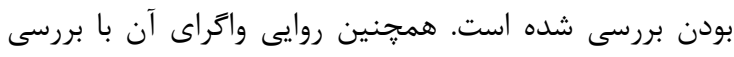

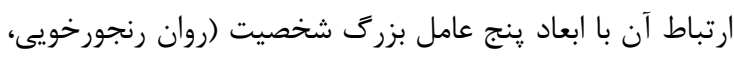

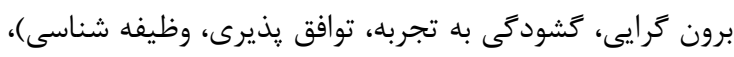

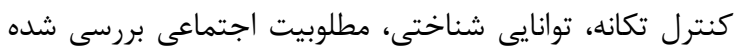

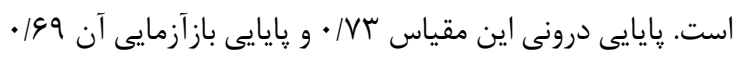

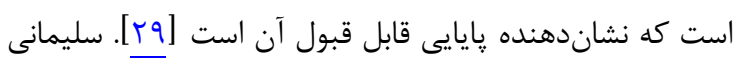

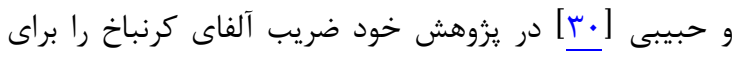

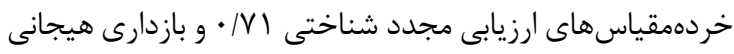

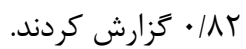

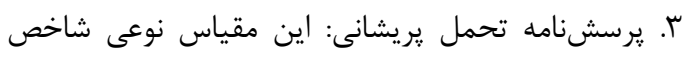

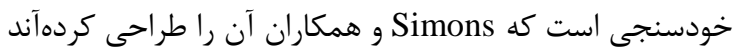
و ها گويه و أ خردهمقياس تحمل (تحمل زيريشانى هيجانى)، جذب (جذبشدن با هيجانات منفى)، ارزيابى (برآورد ذهنى

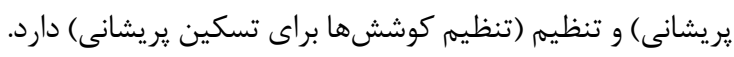




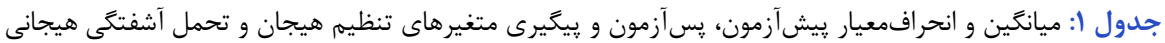

\begin{tabular}{|c|c|c|c|c|c|c|c|}
\hline \multicolumn{2}{|c|}{ يَيَيرى } & \multicolumn{2}{|c|}{ يس آزمون } & \multicolumn{2}{|c|}{ بيش آزمون } & \multirow{2}{*}{ كروه } & \multirow{2}{*}{ متغير } \\
\hline انحرافمعيار & ميانَّين & انحراف معيار & ميانتين & انحرافمعيار & ميانتين & & \\
\hline$\Delta / T V$ & rT/V & $D / F T$ & rr/A & $9 / \pi)$ & Tr/V & كنترل & \\
\hline$r / T F$ & $r r / q$ & $r / 91$ & rv & $r / I F$ & $r r / l$ & آزمايش 1 & ارزيابى \\
\hline$f / \cdot 1$ & 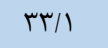 & $r / 9$. & $r F / q$ & $r / v V$ & rT/D & آزمايش r & \\
\hline r/qV & $10 / 0$ & $r / \cdot \Delta$ & $10 / V$ & G/DT & $10 / \Lambda$ & كنترل & \\
\hline f/94 & $19 / 5$ & $4 / 99$ & $r I / r$. & $F / 1$. & 1911 & آزمايش 1 & سر كوبى \\
\hline$r / 4 q$ & 11 & $r / V I$ & $r \cdot N \cdot$ & $r / T V$ & $19 / 4$ & آزمايش r & \\
\hline Q/Dr & FN/T & $\Delta / G Y$ & $F \wedge / D$. & १/V५ & $F \wedge / \Delta$ & كنترل & \\
\hline$\Delta / \cdot \varphi$ & $\Delta r / I$ & $\Delta / \cdot T$ & $\Delta \Lambda / T$. & $F / \Lambda \Lambda$ & $F \wedge / q$ & آزمايش 1 & تنظيم هيجان \\
\hline$\Delta / 1 Q$ & $\Delta 1 / 1$ & D/१९ & $\Delta \Delta / \varepsilon$ & D/AT & $\uparrow \wedge / q$ & آزمايش r & \\
\hline $1 / M \Lambda$ & $1 \cdot / v$ & $r / \cdot \Delta$ & $1 \cdot / v$ & $r / r \Delta$ & $11 / \pi$. & كنترل & \\
\hline$\Gamma / 1 \Lambda$ & $11 / 9$. & $\Gamma / M \Lambda$ & $11 / 9$. & $r / 09$ & $1 \cdot 10$. & آزمايش 1 & \\
\hline$r / 19$ & $11 / \mathrm{V}$ & $r / 19$ & $11 / \mathrm{V}$ & T/IS & $1 \cdot / V \cdot$ & آزمايش r & \\
\hline $1 / \Delta \Lambda$ & $9 / \Delta$ & $1 / 0$ & $9 / 4$. & $1 / \pi \Delta$ & $9 / \pi$. & كنترل & حانات \\
\hline$\cdot / \mathrm{Vr}$ & $1 \cdot 11$ & $\cdot|A|$ & 1. & - IAF & $8 / 4$. & آزمايش 1 & \\
\hline $1 / \Delta T$ & N/I & $1 / \Delta T$ & $V / 9$ & $1 / 0$. & g/4. & آزمايش r & مفلى \\
\hline$\Gamma / \Lambda$. & 19 & $r / V T$ & $11 / 9$. & $\Delta / 9 F$ & 19 & كنترل & \\
\hline$F / r)$ & $r \cdot / V$ & $F / r)$ & $r \cdot / V$ & $r / v$. & $19 / 1$ & آزمايش 1 & بر آورد ذهنى ير يشانى \\
\hline$r / 99$ & TI/A & $4 / .9$ & $r I / F$ & $r / \Lambda$. & $11 / r$ & آزمايش r & \\
\hline T/Re & $\wedge$ & $r / r \Delta$ & $V / 9$ & $r / 4 q$ & $\Lambda / r$ & كنترل & \\
\hline$r / \Delta \cdot$ & $11 / 0$ & $r / Q$. & $11 / 0$ & $r / \cdot V$ & $9 / 9$ & آزمايش 1 & 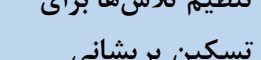 \\
\hline$r|\Delta|$ & $|r /|$ & r/99 & ir & $r / \cdot r$ & $9 / \mathrm{V}$ & آزمايش r & ســين پريسالى \\
\hline F/FG & $F F / T$ & 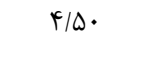 & rr/q & VIAF & $F F / A$ & كنترل & \\
\hline $9 / T V$ & $\Delta F / \tau$ & $9 / 0$. & $\Delta F / 1$ & $F / V \Lambda$ & $\mid 4919$ & آزمايش 1 & \\
\hline $91 \cdot r$ & $\Delta F / V$ & s/4 & $\Delta r$ & 9199 & id & آزمايش r & \\
\hline
\end{tabular}

كبتر آزمون براى هريك از متغيرها معنادار است، ولى در كروه

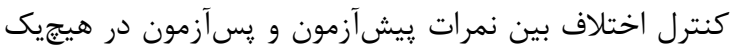

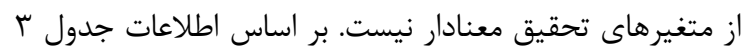

معنى دارى متفاوت از گروه كنترل است.

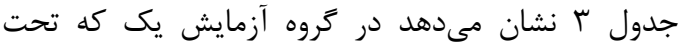

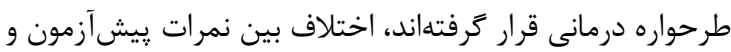
جدول r: تحليل واريانس با اندازهگيرى مكرر براى مقايسه بِيشآزمون، يس آزمون و پِيخيرى متغيرهاى تنظيم هيجانى و تحمل بريشانى در كروهاى آزمايش يك و كنترل

\begin{tabular}{|c|c|c|c|c|c|c|c|}
\hline طر حواره درمانى اتى & معنادارى & $\mathbf{F}$ & مجذانَين & آزادى & مجذمورات & منبع اثر & مقياس \\
\hline \multirow[t]{2}{*}{$\cdot / r \cdot 4$} & \multirow[t]{2}{*}{.1 .19} & \multirow[t]{2}{*}{$F / 9 V$} & $\Delta S \mid \wedge \varphi$ & $r$ & $11 \% / V r$ & \multirow{2}{*}{ خرحله خطروه } & \\
\hline & & & $I T / 1 V$ & re & FrN/F. & & \\
\hline \multirow[t]{2}{*}{$\cdot \mid r q 1$} & \multirow[t]{2}{*}{$.1 \cdot 1 f$} & \multirow[t]{2}{*}{$V / 4 \cdot 1$} & $11 \cdot / \pi q$ & 1 & $11 \cdot / 49$ & كروه & \\
\hline & & & $\Lambda \cdot \mid G T$ & 11 & FrN/F. & خطا & \\
\hline$\cdot / T \wedge \Delta$ & . $\cdot r$ & $V / 199$ & $V I / V I$ & r & | & مرحله & \multirow{5}{*}{ هيجان } \\
\hline \multirow[t]{2}{*}{$\cdot$ / TVG } & \multirow[t]{2}{*}{$\cdot / \cdot r$} & \multirow[t]{2}{*}{ g/AV } & $8 / 1 \Lambda 1$ & r & IrV/gr & مرحله* كروه & \\
\hline & & & $1 \cdot \% v$ & re & $r G \cdot / T G$ & خطا & \\
\hline \multirow[t]{2}{*}{$\cdot|r| V$} & \multirow[t]{2}{*}{.$/ \cdot \mu$} & \multirow[t]{2}{*}{$\Delta / \cdots 1$} & $F \wedge 1 / 99$ & 1 & $\mid 41 / 99$ & كروه & \\
\hline & & & $98 / \pi)$ & 11 & IVTr/VT & خطا & \\
\hline . & $.1 \cdot 1 \mathrm{f}$ & $F / \wedge \& q$ & $\Delta S / T G$ & $r$ & $1 / r / \Delta T$ & مرحله & \multirow{5}{*}{ تحري } \\
\hline \multirow[t]{2}{*}{.$/ r q \Lambda$} & \multirow[t]{2}{*}{$\% r$} & \multirow[t]{2}{*}{$V / 9 \Delta \Lambda$} & $\Lambda \mathrm{N} / \wedge \varphi$ & r & IVV/VT & مرحله*تروه & \\
\hline & & & $11 / 9 \cdot 4$ & rq & FIV/VR & خطا & \\
\hline \multirow[t]{2}{*}{$\cdot / r \vee \wedge$} & \multirow[t]{2}{*}{ 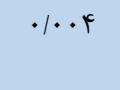 } & \multirow[t]{2}{*}{ 1./9rब } & $111 / 99$ & 1 & $1 M 1 / 99$ & كروه & \\
\hline & & & $\lambda \cdot \mid \varepsilon r$ & 11 & $|F \Delta| / T \&$ & خطا & \\
\hline
\end{tabular}


جدول با: نتايج آزمون مقايسه زوجى براى مقايسه ميانخين متغيرها در طرحواره درمانى با گروه كنترل

\begin{tabular}{|c|c|c|c|c|c|}
\hline بيگيرى & يس آزمون & بيش آزمون & مر احل & تروه & متغير \\
\hline$T / T \cdot *$ & 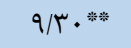 & --- & يِيشآزمون & & \multirow{4}{*}{ تنظيم هيجان } \\
\hline$\cdot / r \cdot$ & --- & $-9 / \Gamma \cdot \frac{* *}{* * *}$ & يس آزمون & & \\
\hline$-\cdot / r$ & . & ---- & קيشآزمون & \multirow{2}{*}{ كنترل } & \\
\hline$-\cdot / r \cdot$ & ---- & . & پس آزمون & & \\
\hline $9 / 9 . * * \%$ & $9 / 0 \cdot * * *$ & ---- & קِيش آزمون & \multirow{2}{*}{ آزمايش } & \multirow{4}{*}{ تحمل يريشانى } \\
\hline .11. & --- & $-9 / 0 \cdot \cdots$ & يس آزمون & & \\
\hline$-\cdot 19$. &.$- / 9$. & ---- & يِيشآزمون & \multirow{2}{*}{ كنترل } & \\
\hline$\cdot / \mu$ & ---- & .19 . & يس آزمون & & \\
\hline
\end{tabular}

ييخيرى در اين گروهها تفاوت معنادارى مشاهده مىشود

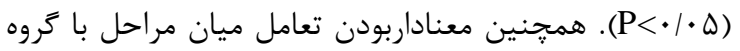

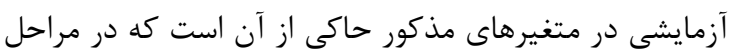

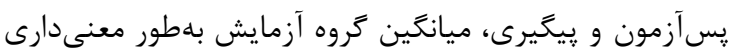
متفاوت از گروه كنترل است.

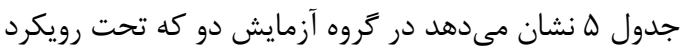

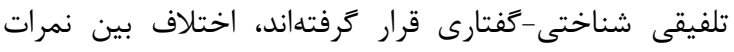

بين نمرات يسآزمون و پييگيرى در گروه آزمايش يك نيز اختلاف

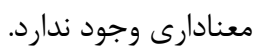

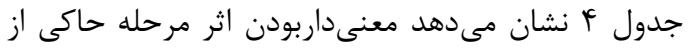

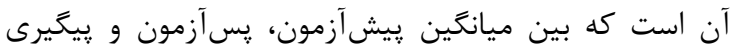

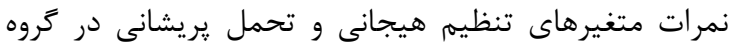

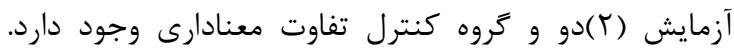

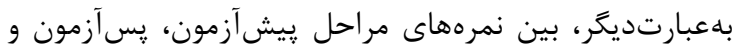

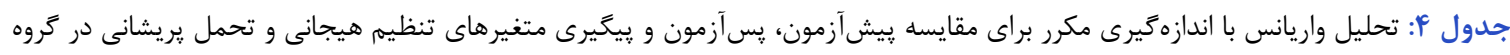
آزمايش دو و كنترل

\begin{tabular}{|c|c|c|c|c|c|c|c|}
\hline رويكرد تلفيقى & معنادارى & $\mathbf{F}$ & مجذانگين & آزادى & مجذمورع & منبع اثر & مقياس \\
\hline שTR & $.1 \cdot 11$ & $\Delta / / Q$ & $r V|q|$ & r & $V D / T M$ & مرحله & \multirow{5}{*}{ تنظيم } \\
\hline \multirow[t]{2}{*}{$\cdot / r \cdot r$} & \multirow[t]{2}{*}{.$/ \cdot I V$} & \multirow[t]{2}{*}{$\varphi / \Delta \varphi$} & ו וT/K & r & 99194 & مرحله تروه & \\
\hline & & & $\mathrm{V} / \mathrm{r}$. & rq & TET/A. & خطا & \\
\hline \multirow[t]{2}{*}{.$/ 114$} & \multirow[t]{2}{*}{$\cdot 1 \cdot+\lambda$} & \multirow[t]{2}{*}{$r / r \wedge 1$} & \multirow[t]{2}{*}{ rDS/RG } & 1 & TDG/TG & كروه & \\
\hline & & & & 11 & T. Tr & خطا & \\
\hline & $\cdot 1 \cdot \cdot 1$ & $1 / 19$ & $19 / \cdot 1$ & $r$ & $|V N| \cdot r$ & مرحله & \multirow{5}{*}{ تحمل } \\
\hline \multirow[t]{2}{*}{$\cdot|r q|$} & \multirow[t]{2}{*}{$\cdot 1 \cdot \cdot 1$} & \multirow[t]{2}{*}{$11 / \Delta 9$} & $|r \Delta / V|$ & r & rDI/Fr & مرحله حقروه & \\
\hline & & & $1 \cdot 119$ & re & $r q 1 / r$. & خطا & \\
\hline \multirow[t]{2}{*}{$\cdot / r \cdot V$} & \multirow[t]{2}{*}{$.1 \cdot 11$} & \multirow[t]{2}{*}{$V / 94 \Lambda$} & \multirow[t]{2}{*}{$V Y T / \cdot G$} & 1 & $V T / / .9$ & تروه & \\
\hline & & & & 11 & 1949 & خطا & \\
\hline
\end{tabular}

جدول ه: نتايج آزمون مقايسه زوجى براى مقايسه ميانگَين متغيرها در رويكرد تلفيقى با كروه كنترل

\begin{tabular}{|c|c|c|c|c|c|}
\hline بيخيرى & بس آزمون & بيش آزمون & مراحل & تروه & متغير \\
\hline$\cdot / \pi$ & $G / V^{* * *}$ & --- & ييشآزمون & \multirow[b]{2}{*}{ آزمايش } & \multirow{4}{*}{ تنظيم هيجان } \\
\hline$-F / \Delta$ & --- & $-9 / V^{* * *}$ & ֶسآزمون & & \\
\hline$-\cdot / \Gamma \cdot$ & • & ---- & ِيش آزمون & \multirow{2}{*}{ كنترل } & \\
\hline$-\cdot / \mu \cdot$ & ---- & . & ֶسآزمون & & \\
\hline$\Lambda / V^{* \text { *ै* }}$ & $V^{* * *}$ & ---- & يِش آزمون & \multirow{2}{*}{ آزمايش } & \multirow{4}{*}{ تحمل يريشانى } \\
\hline $1 / V^{*}$ & --- & $-V^{* * * *}$ & ֶسآزمون & & \\
\hline$-\cdot 19$ &.$- / 9$. & ---- & پيش آزمون & \multirow{2}{*}{ كنترل } & \\
\hline$\cdot / r$ & ---- & .19. & هسآزمون & & \\
\hline
\end{tabular}


جدول و: تحليل واريانس با اندازمَيرى مكرر براى مقايسه بيشآزمون، يس آزمون و يِيكيرى متغيرهاى تنظيم هيجانى و تحمل بريشانى در تروهاى

\begin{tabular}{|c|c|c|c|c|c|c|c|}
\hline مجذور اتا براى مقايسه طرحواره & معنادارى & $\mathbf{F}$ & مجذانتَين & آزادى & مجذورات & منبع اثر & مقياس \\
\hline$\cdot / N T \Delta$ & $\cdot 1 \cdot .1$ & $<q / \wedge \uparrow q$ & $r \cdot 1 / 9$. & $r$ & $r \cdot r / r$ & مرحله & \multirow{5}{*}{ هيجان } \\
\hline \multirow[t]{2}{*}{. } & .1119 & $r / r q 1$ & $9 / Y q V$ & r & IN/Ar & مرحله كروه & \\
\hline & & & $F / . \mu q$ & re & $\mid f \Delta / 9$. & خطا & \\
\hline \multirow[t]{2}{*}{.$/ \cdot r_{\Delta}$} & $\cdot 10 \cdot 1$ & $\cdot \mid \varphi \Delta \varphi$ & $r \Delta / r \varepsilon$ & 1 & rQ/TS & كروه & \\
\hline & & & VV/rr & 11 & Irar & خطا & \\
\hline.$/ 914$ &.$/ . .1$ & $|N \Lambda / \Lambda|$ & $r F q / 9 D$ & r & $999 / \Gamma$. & مرحله & \multirow{5}{*}{ 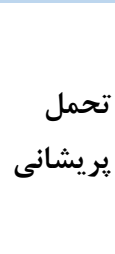 } \\
\hline . /lar & $\cdot|\cdot \Delta|$ & $r / r<q$ & $91.1 \mathrm{~V}$ & r & $\mid r / \cdot r r T$ & مرحله:تروه & \\
\hline \multirow{3}{*}{$\cdot \cdot \cdot r$} & & & I/NAT & rद & $99199 \mathrm{~V}$ & خطا & \\
\hline &.$/ v 9$. & $.1 \cdot V r$ & $N 1.9 \mathrm{~V}$ & 1 & $N / \cdot 9 V$ & تروه & \\
\hline & & & $11 \cdot / \Delta V^{F}$ & 11 & $199 \cdot / r r$ & خطا & \\
\hline
\end{tabular}

$\mathrm{P}<\cdot / \cdot \Delta: *$

بابايى [بـ[ب] و Tai-Wa] همسويى و همخوانى دارد.

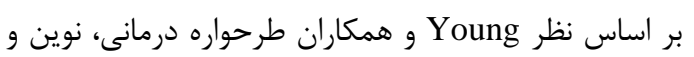

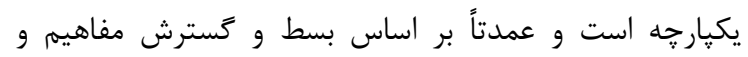
روشهاى درمان شناختى-رفتارى كلاسيك بنا شده است است

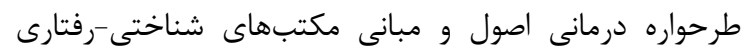

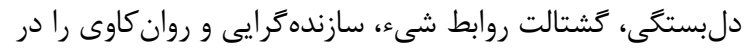

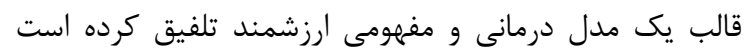

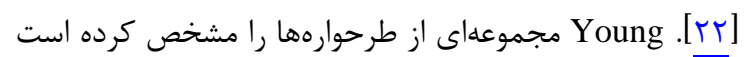

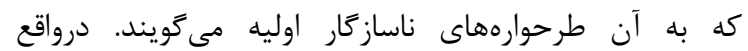

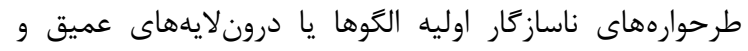

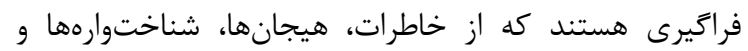

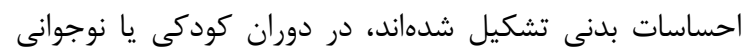

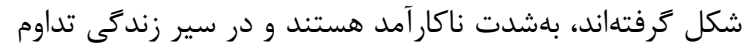

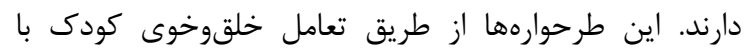

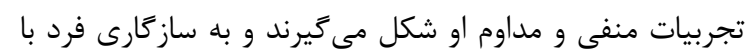

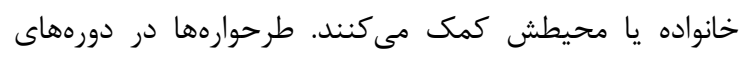

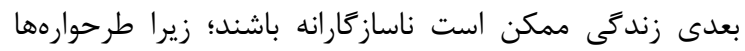

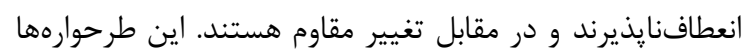

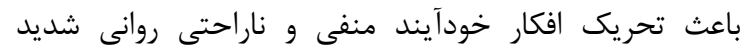

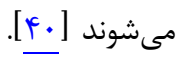
در تبيين نتايج مذكور مى توان كَفت كه طرحواره درمانى با

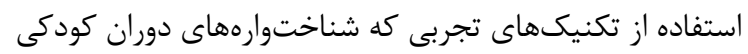

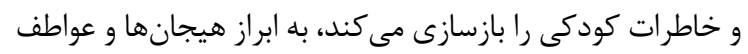

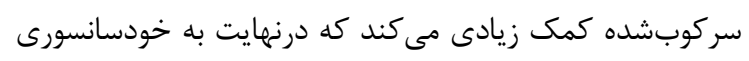

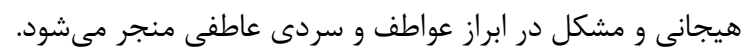

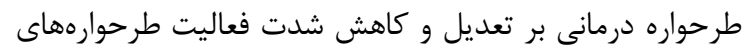

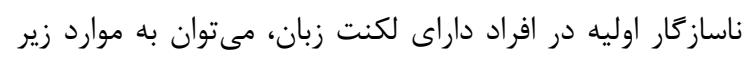

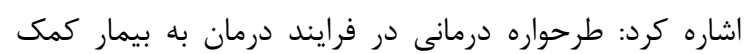

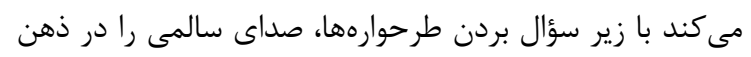

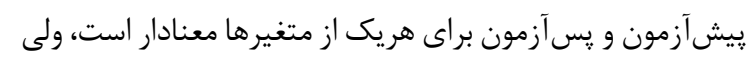

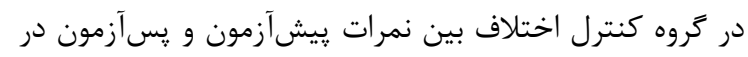

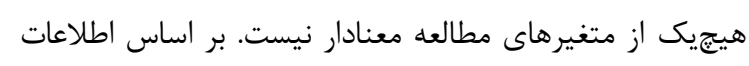

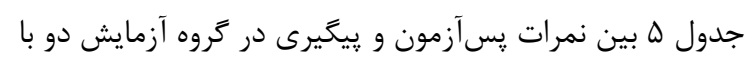

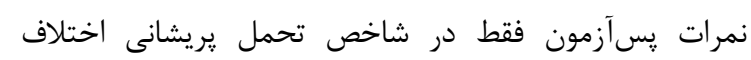

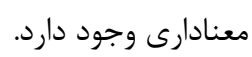

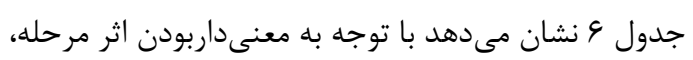

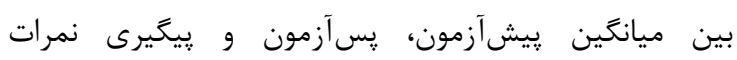

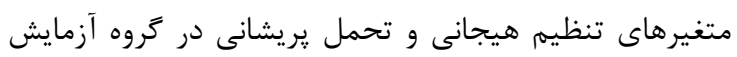

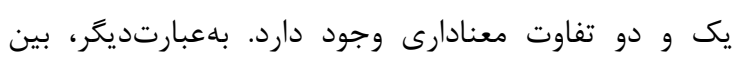

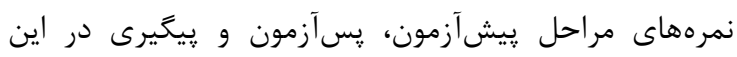

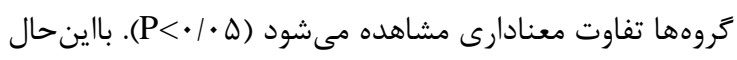

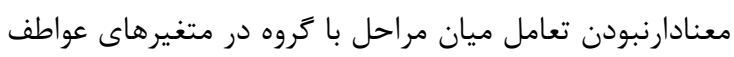

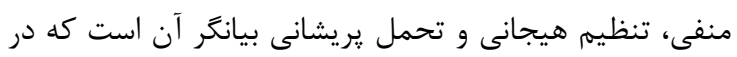

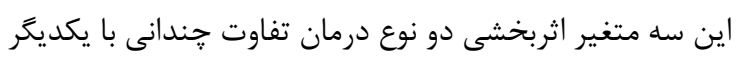
نداشتند.

بִ مطالعه حاضر بهمنظور مقايسه اثربخشى طرحواره درمانى تحمي

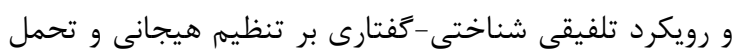

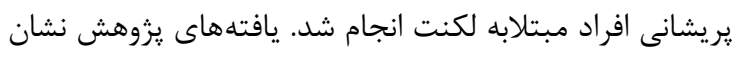

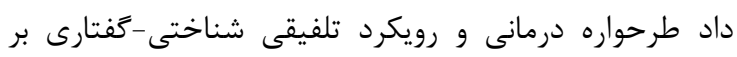

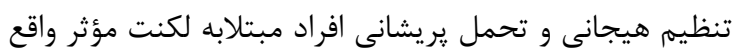

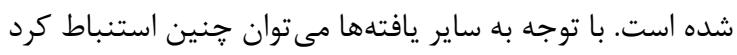

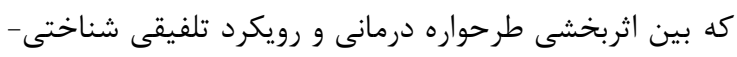

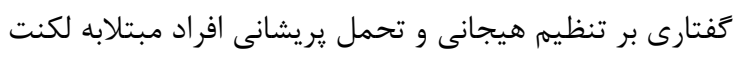

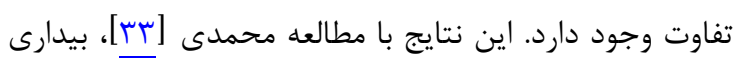

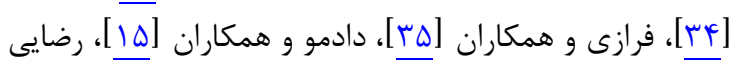

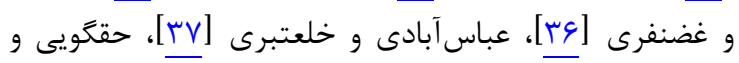


اضطراب، اجتناب، هيجانات منفى و غيره مىداند. طبق اين

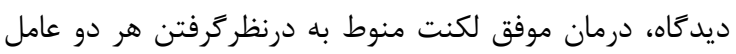

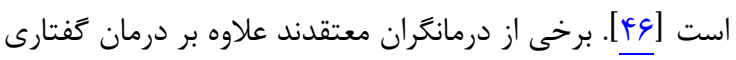

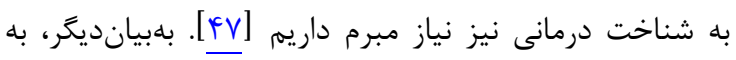

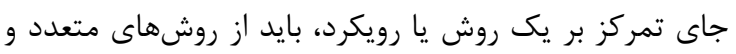

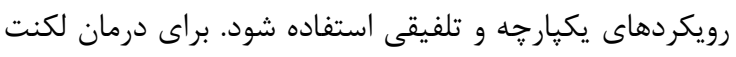

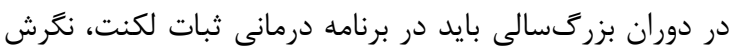

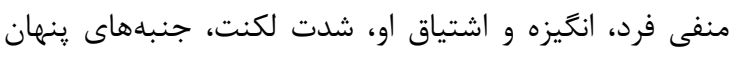

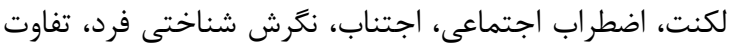

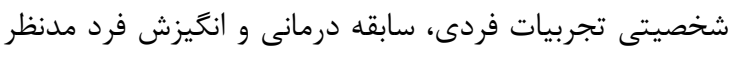

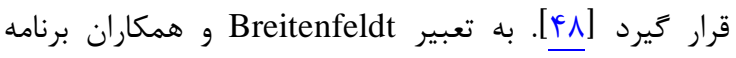

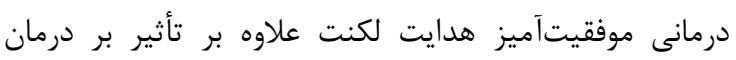

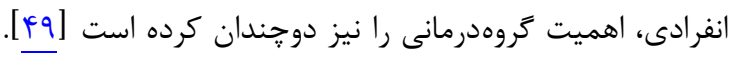

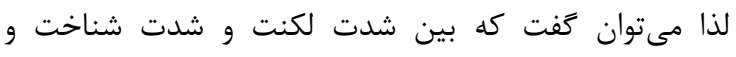

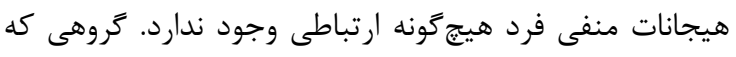

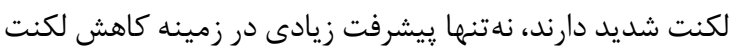

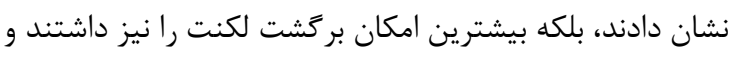
بين گروهى كه هيجانات خفيف داشتند با گروهى كه هيجانات دئن

شديد داشتند، تفاوتهاى هيجانى -شناختى وجود نداشت

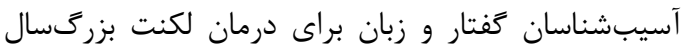

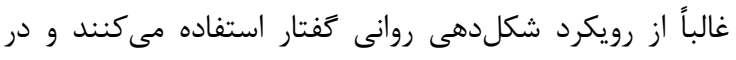
بيشتر مواقع با بازگشت لكنت مواجه ميى شوند. اين معضل روان همواره

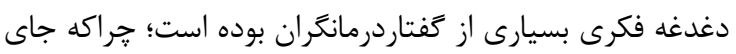
خالى يك رويكرد جامع و تلفيقى مركب از رويكرد درمان شناختى-رفتارى و رويكردهاى سنتى در مجامع علمى و مراكز بالينى احساس مىشد. در اين يزوهش، رويكردهاى مختلف

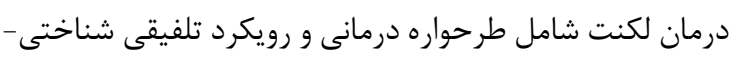
كَفتارى بررسى شد. در مقايسه اين دو درمان مى توان كَّان

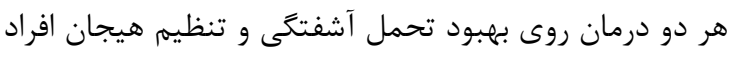

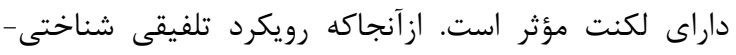

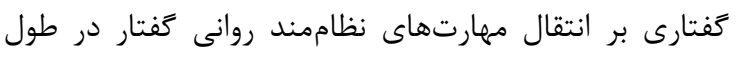

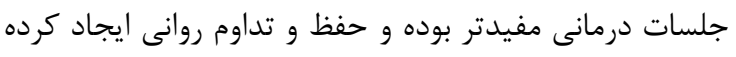

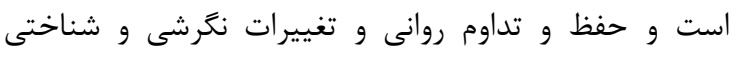

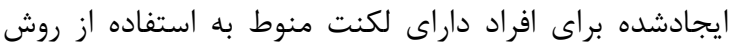

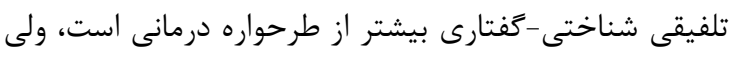

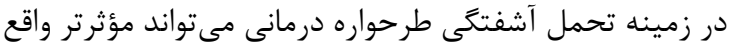

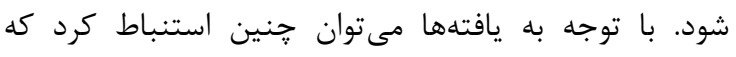

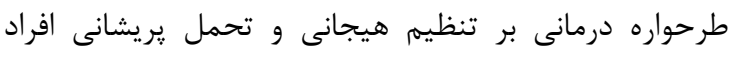

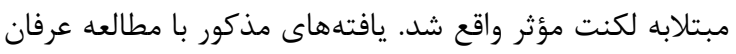

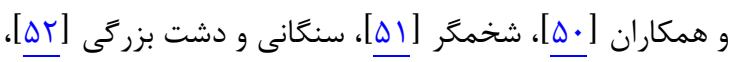

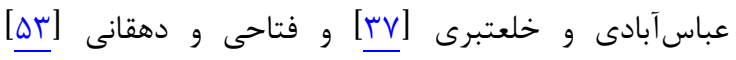
همسويى و همخوانى دارد.

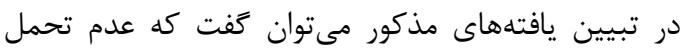

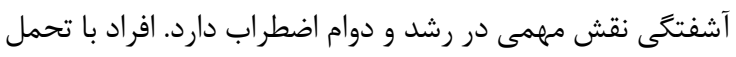

خود به وجود بياورد و بدين ترتيب ذهنيت سالم خود را توانمند

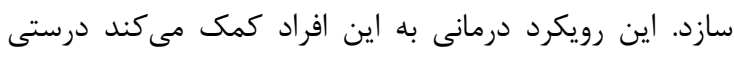

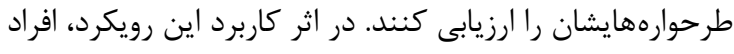

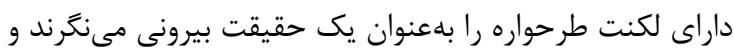

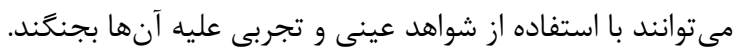

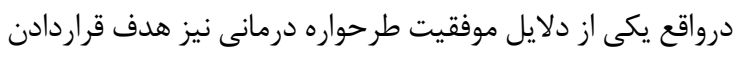

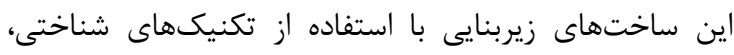
رفتارى و تجربى است. طرحواره درمانى با تأكيد بر تغيير طرحوارههاى ناساز

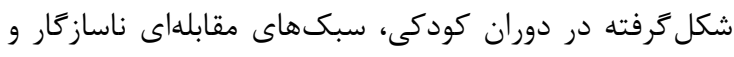

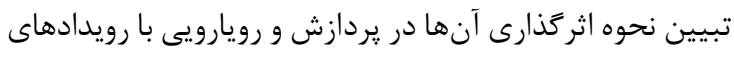

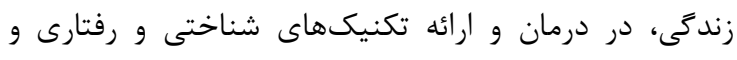

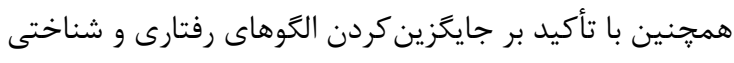

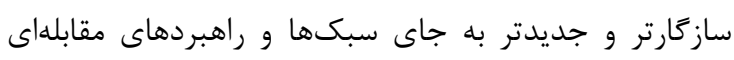

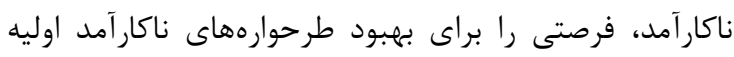

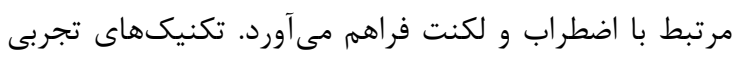

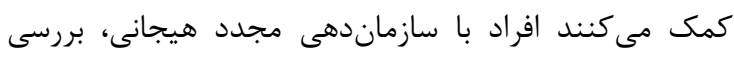

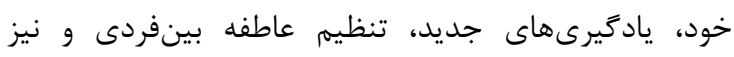

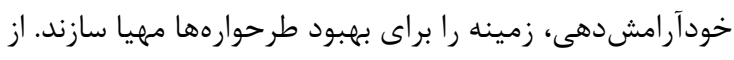

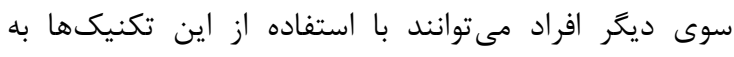

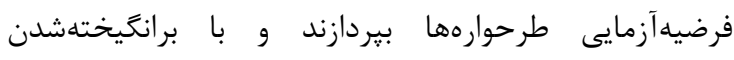

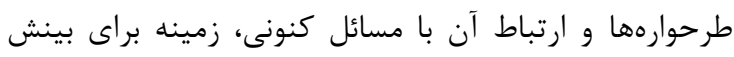
هيجانى و متعاقب آن بهبود طرحوارهارها مها مهيا شود.

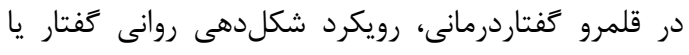

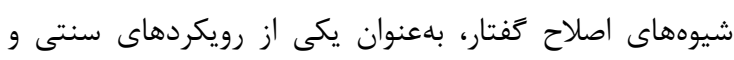

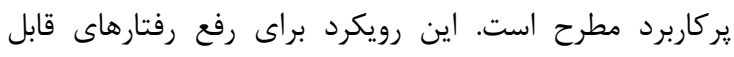

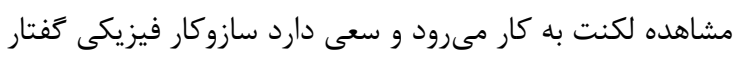
فرد را تغيير دهد. اين تغييرات شامل سرعت كفتار، ريتم كفتار،

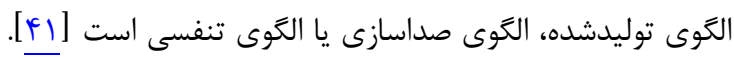
Blomgren

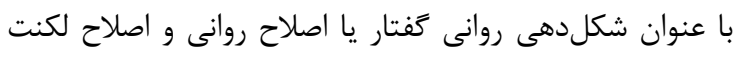
شرح دادهاند. بازسازى شناختى نيز رويكرد ديخرى است كه بهطور مستقل

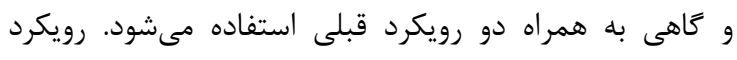

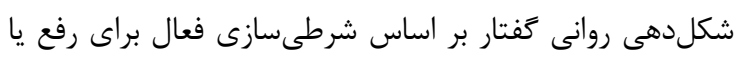

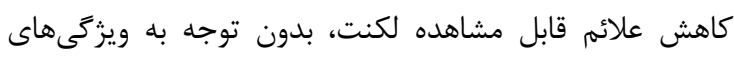

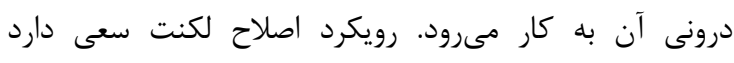

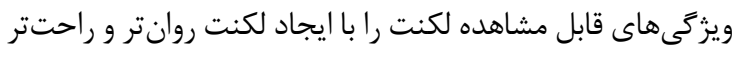

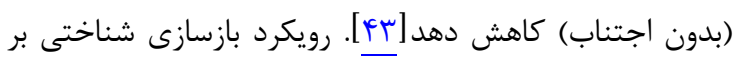

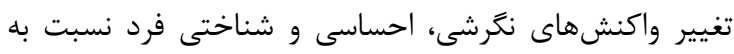

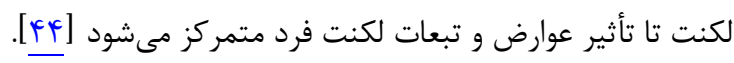

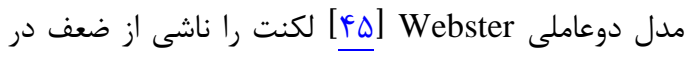
ناحيه حركتى مكمل نيمكره جِ

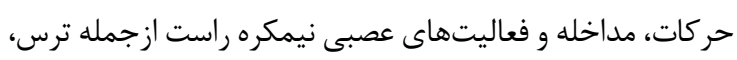


واردشده، ناتوانى در كنترل احساسات و رشدنيافتكى و عدم

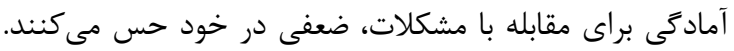

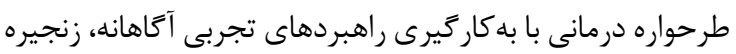

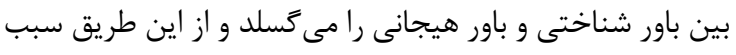

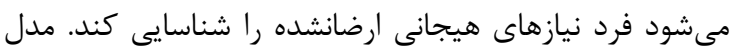

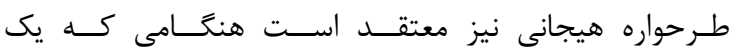

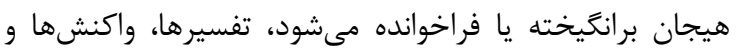

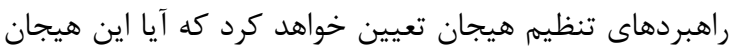

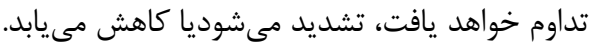

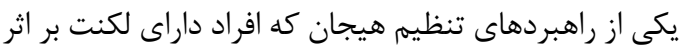

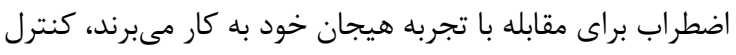

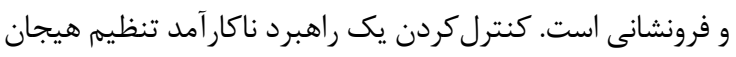

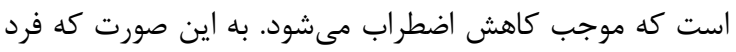

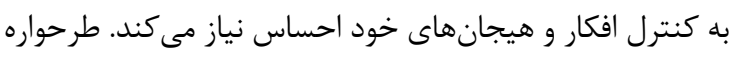

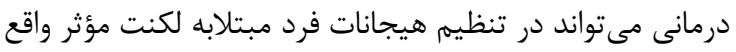

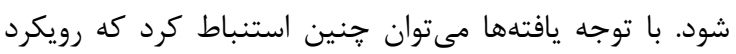

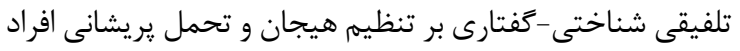

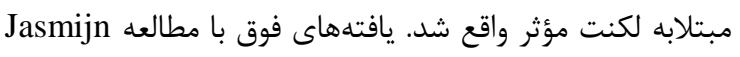

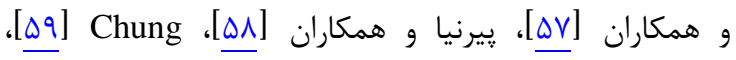

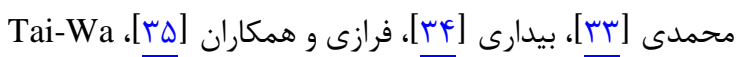

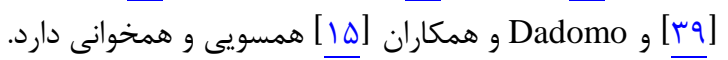

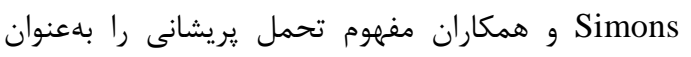

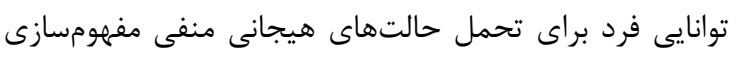

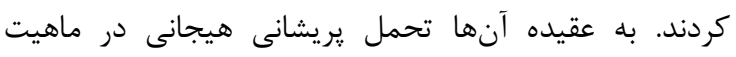

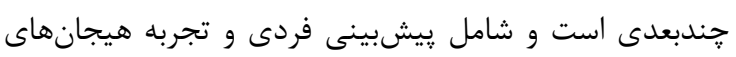

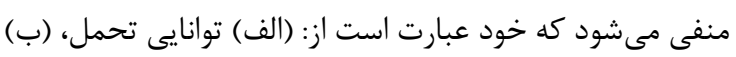

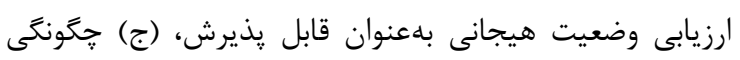

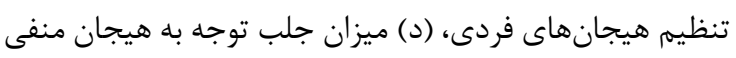

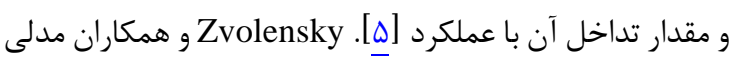

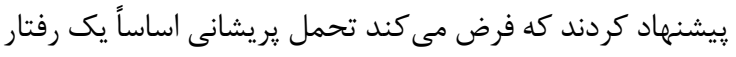

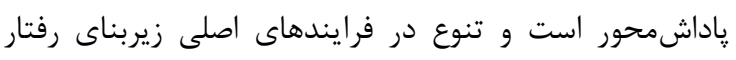

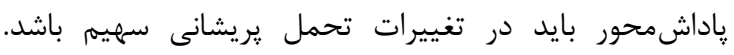

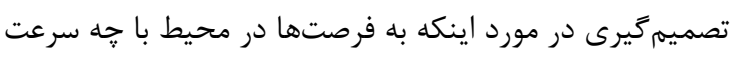

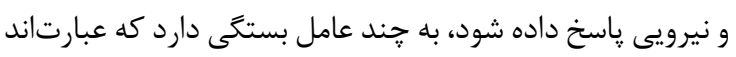

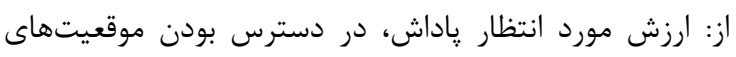

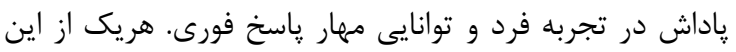

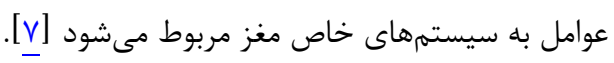

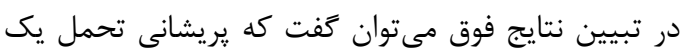

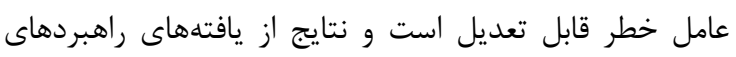

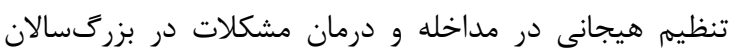

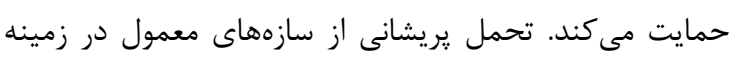

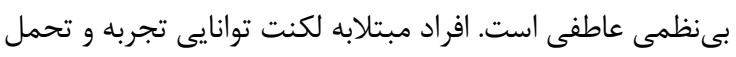

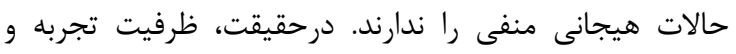

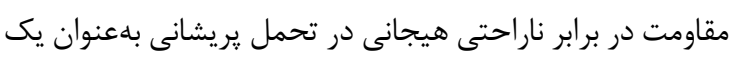

آشفتگى بالا قادر هستند حالات روانشناختى منفى را تحمل

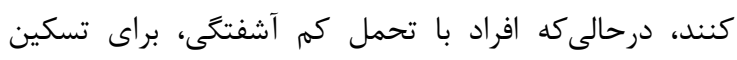

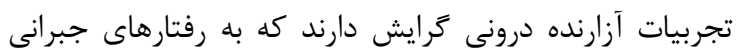

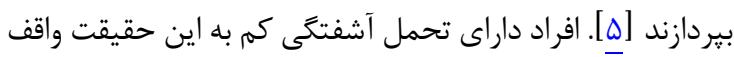

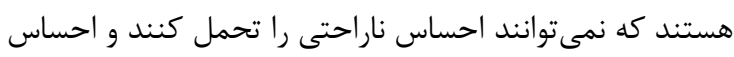

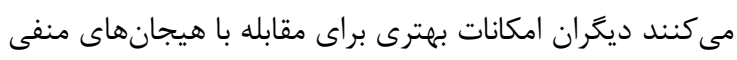
دارند [مبا].

ازآنجاكه افراد داراى اختلال لكنت در روابط خود دجار مشكل

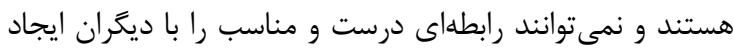

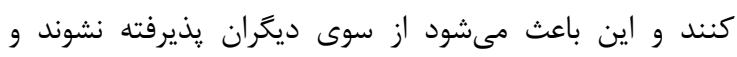

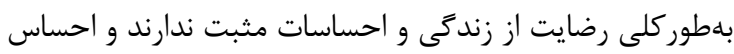

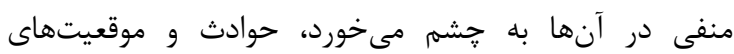

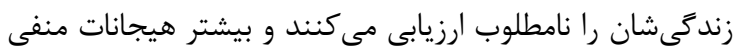

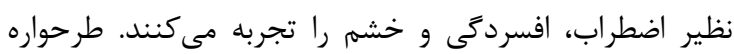

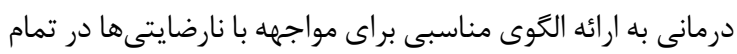

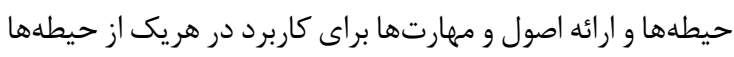

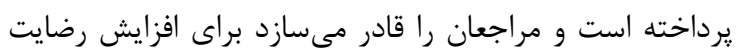

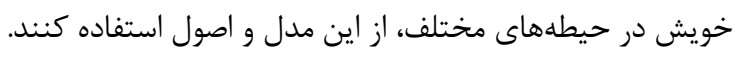

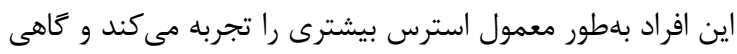

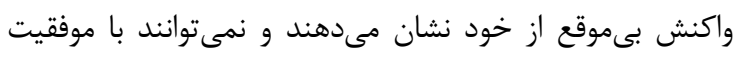

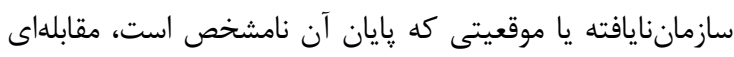

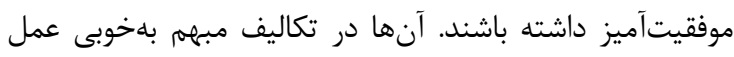

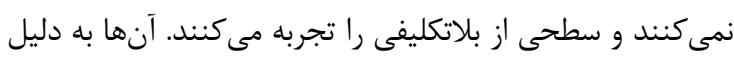

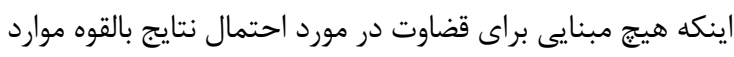

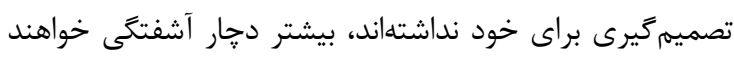

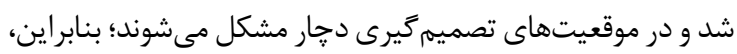

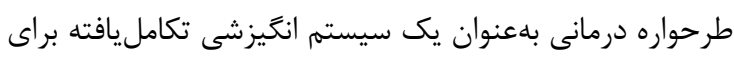

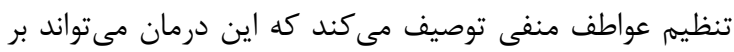

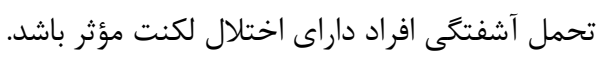

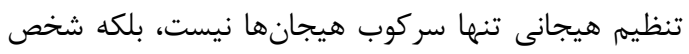

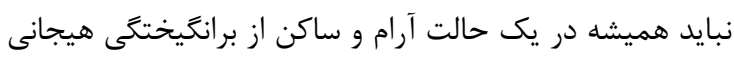

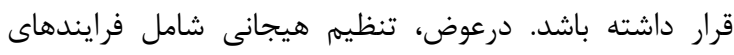

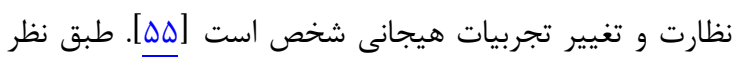

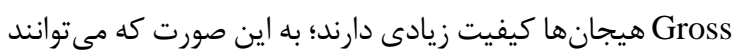

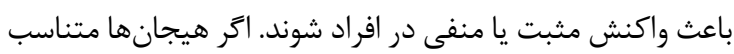

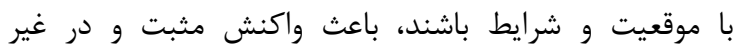

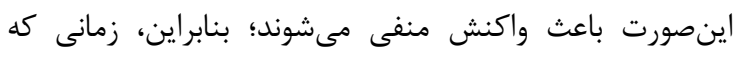
هيجانها شديد يا طولانى مى شوند يا با شرايط سازئ آنار نيستند،

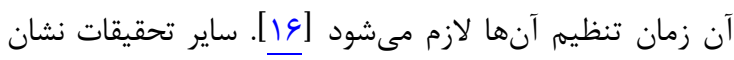

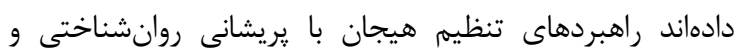
تكانشكرى مرتبط است [عهان].

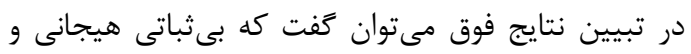

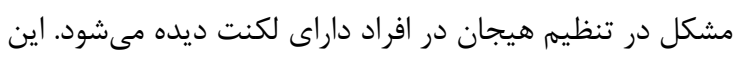

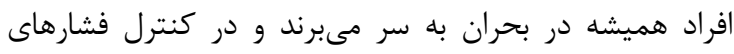


مثبت، تغيير عمدهاى در طرحوارهها و مسائل شناختى اين افراد

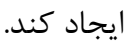
ييشنهاد مىشود يزوهشهاى مشابه ديخر با نمونههاى بالينى

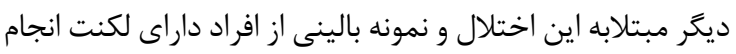

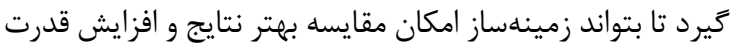

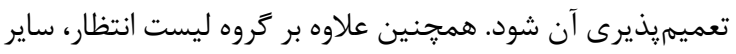

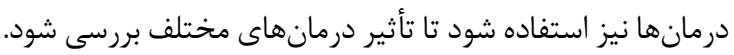

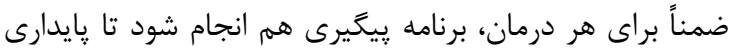

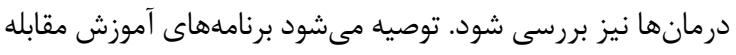

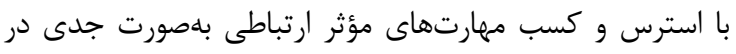

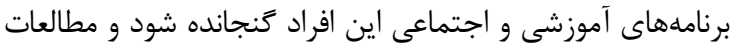

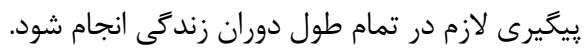

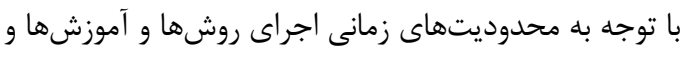
بهكاركيرى فنون آموزشى مورد نياز براى ساير مشكلات آزمودنى هـانها

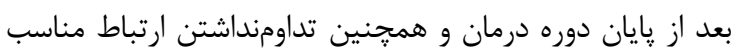

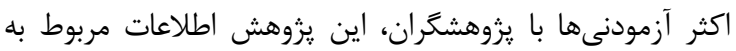
ارزيابى هاى طول دوره درمان راندارد.

\section{نتيجه تيرى}

درمجموع نتايج اين مطالعه نشان داد تنظيم هيجان و تحمل

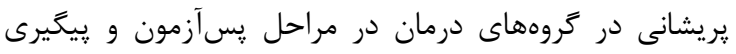

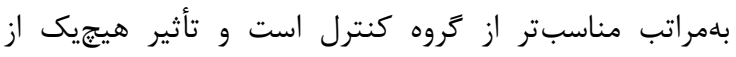

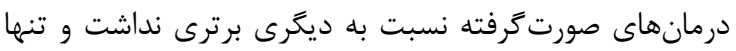

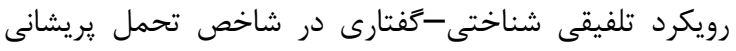

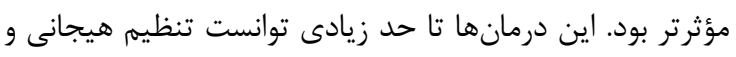

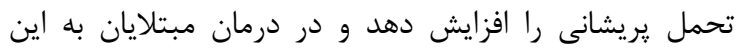
اختلال به كار زرفته شود.

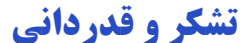

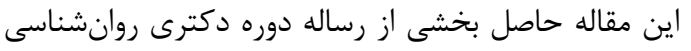

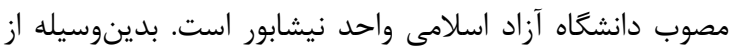

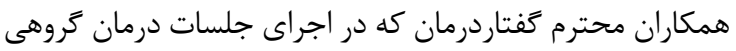
رويكرد تلفيقى شناختى-كفتارى همكارى صميمانهاى داشتند،

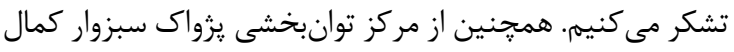
تشكر و سياسگزارى را داريم.

تضاد منافع

نتايج اين يزوهش با منافع نويسند

\section{ملا حظات اخلاقى}

اين مطالعه در مركز كارآزمايىهاى بالينى ايران با شماره

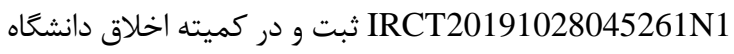

آزاد نيشابور بررسى و با كد اخلاق IR.IAU.NEYSHA BUR.REC.1399.006 تأييد شده است. ناست كدر اخلاق
ساختار در آنها ديده نمىشود.

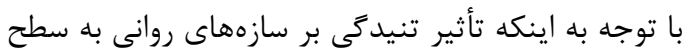

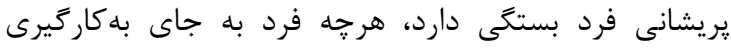

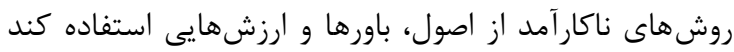

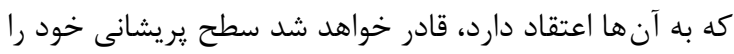
افزايش دهد. ازاينرو قدم اول در شناختدرمانى، آنَاهكردن

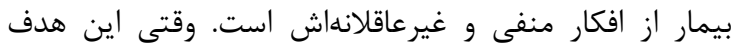

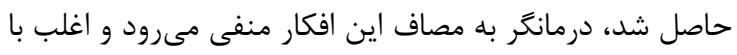

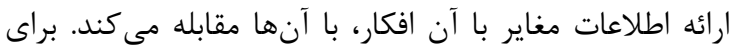
اجراى اين مقصود مى توان مشكل بيمار را به شكلى ديخر در آورد

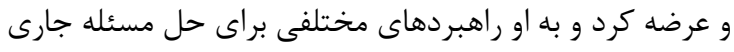

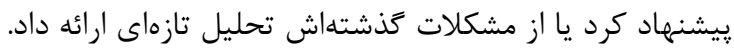

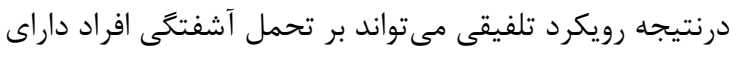
اختلال لكنت مؤثر باشد.

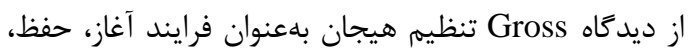

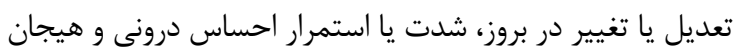

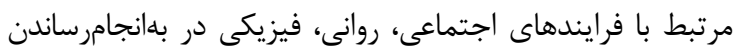

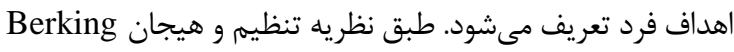

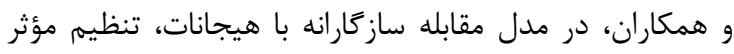

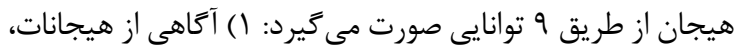

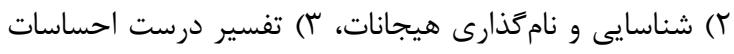

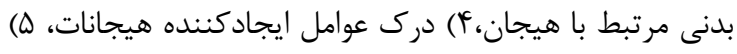

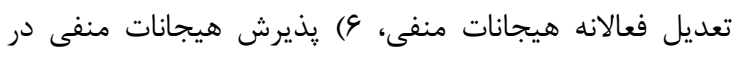

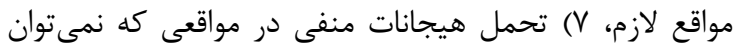

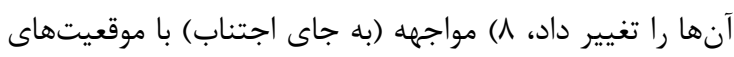
ير يشان كننده به خاطر كسب اهداف مهلم و 9 9) حمايت دلسوزانه

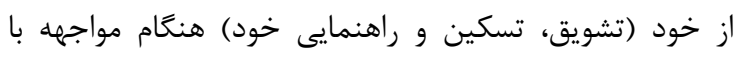

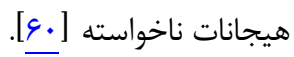

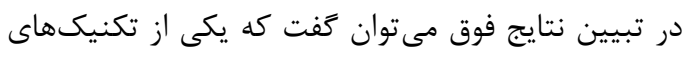

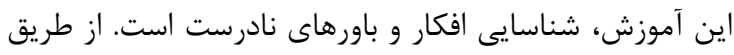

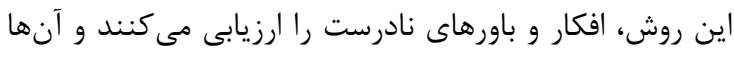

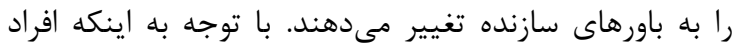

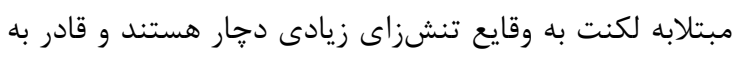

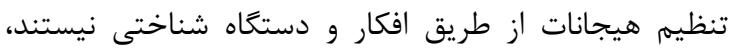

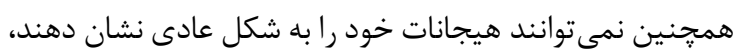

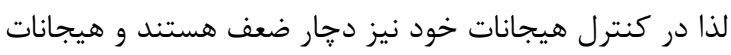

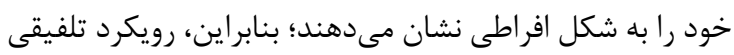

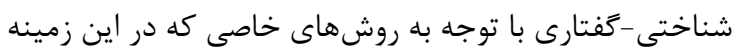

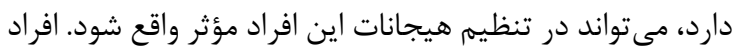

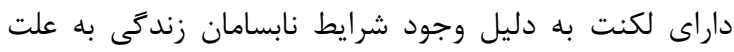
ضعف در سركوب هيجانات و مشكلات هيجانى كه در آنها

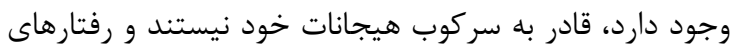

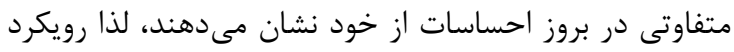

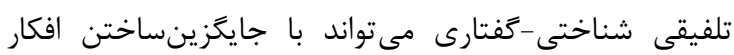




$$
\begin{aligned}
& \text { درصد)؛ نويسنده جهارم (يروهشگر همكار): مشاركت در اجراى } \\
& \text { طرح و نعارش مقاله (• (1 درصد). } \\
& \text { حمايت مالَى } \\
& \text { مركز توانبخشى يزواك سبزوار از اين تروزة حمايت مالى } \\
& \text { كرده است. }
\end{aligned}
$$

$$
\begin{aligned}
& \text { سمهم ذويسنلكَ' }
\end{aligned}
$$

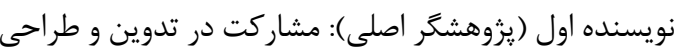

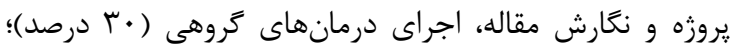

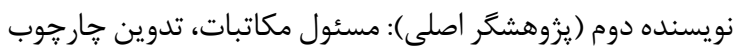

$$
\begin{aligned}
& \text { كلى طرح، نعارش مقدمه، تجزيهوتحليل آمارى، تدوين نتايج و }
\end{aligned}
$$

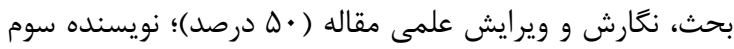

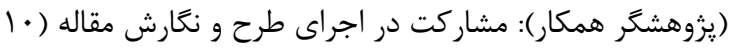

\section{REFERENCES}

1. Yairi E, Ambrose N. Epidemiology of stuttering: 21st century advances. J Fluency Disord. 2013;38(2):66-87. PMID: 23773662 DOI: 10.1016/j.jfludis.2012.11.002

2. Craig-McQuaide A, Akram H, Zrinzo L, Tripoliti E. A review of brain circuitries involved in stuttering. Front Hum Neurosci. 2014;8:884. PMID: 25452719 DOI: 10.3389/ fnhum.2014.00884

3. Neef N, Linh Hoang T, Need A, Paulus W, Sommer M. Speech dynamics are coded in the left motor cortex in fluent speakers but not in adults who stutter. Brain. 2015; 138(3):712-25. PMID: 25595146 DOI: 10.1093/brain/ awu390

4. Abyar Z, Ahmadi Nasrabad Sofla S, Mousavi Kia SS, Zamani $\mathrm{N}$. The effect of stress tolerance, alertness, emotion regulation and interpersonal efficiency training on risky behaviors, depression, anxiety and stress in children with stuttering. $J$ Health Res. 2019;4(3):145-51. DOI: $10.29252 / \mathrm{hrjbaq} .4 .3 .145$

5. Simons J, Gaher, R. The Distress tolerance scale: development and validation of a self-report measure. Motiv Emot. 2005;29(2):83-102. DOI: 10.1007/s11031-005-7955-3

6. O'Cleirigh $\mathrm{C}$, Ironson $\mathrm{G}$, Smits JA. Does distress toleranc moderate the impact of major life events on psychosocial variables and behaviors important in the management of HIV. Behav Ther. 2007;38(3):314-23. PMID: 17697855 DOI: 10.1016/j.beth.2006.11.001

7. Zvolensky MJ, Bernstein A, Vujanovic AA. Distress tolerance: theory, research, and clinical application. New York: Guilford Press; 2011.

8. Kelishadi F, Yazdkhasti F. Impact of perception of parental rejection-acceptance and control on moral intelligence and distress tolerance. Strategy Culture. 2016;9(33):155-69.

9. Ntourou K, Conture EG, Walden TA. Emotional reactivity and regulation in preschool-age children who stutter. $J$ Fluency Disord. 2013;38(3):260-74. PMID: 24238388 DOI: 10.1016/j.jfludis.2013.06.002

10. DePape AM, Lindsay S. Parents' experiences of caring for a child with autism spectrum disorder. Qual Health Res. 2015;25(4):569-83. PMID: 25246329 DOI: $10.1177 / 104973$ 2314552455

11. Wimez B, Pina W. The assessment of emotion regulation improving construct validity in research on psychopathology in yoth. J Psychol Behav Assess. 2015;32(1):1-7.

12. Otto B, Misra S, Prasad A, McRae K. Functional overlap of top-down emotion regulation and generation: an fMRI study identifying common neural substrates between cognitive reappraisal and cognitively generated emotions. Cogn Affect Behav Neurosci. 2014;14(3):923-38. PMID: 24430617 DOI: 10.3758/s13415-013-0240-0

13. Brans K, Koval P, Verduyn P, Lim YL, Kuppens P. The regulation of negative and positive affect in daily life. Emotion. 2013;13(5):926-39. PMID: 23731436 DOI: $10.1037 / \mathrm{a} 0032400$

14. Grecucci A, Thneuick A, Frederickson J, Job R. Mechanisms of social emotion regulation: from neuroscience to psychotherapy. Emotion regulation: processes, cognitive effects and social consequences. New York: Nova Publishing; 2015. P. 57-84.

15. Dadomo H, Grecucci A, Giardini I, Ugolini E, Carmelita A, Panzeri M. Schema therapy for emotional dysregulation: theoretical implication and clinical application. Front Psychol. 2016;7:1987. PMID: 28066304 DOI: 10.3389/ fpsyg.2016.01987

16. Gross JJ, Muñoz RF. Emotion regulation and mental health. Clin Psychol Sci Pract. 1995;2(2):151-64. DOI: 10.1111/j.1468-2850.1995.tb00036.x

17. Nasri B, Castenfors M, Fredlund P, Ginsberg Y, Lindefors N, Kaldo V. Group treatment for adults with ADHD based on a novel combination of cognitive and dialectical behavior interventions: a feasibility study. J Attent Disord. 2020; 24(6):904-17. PMID: 28178870 DOI: 10.1177/10870 $\underline{54717690231}$

18. Farazi M, Tehrani LG, Koolaee AK, Shemshadi H, Rahgozar M. Effectiveness of integrated cognitive - speech approaches to the treatment of adult stuttering. Speech Lang Pathol. 2015;1(2):8-18. [Persian]

19. Farazi M. Stuttering at a glance. Tehran: Roshd Farhang; 2017. [Persian]

20. Safari Hafshejani Z, Khoramshahi H. A review of effective treatments for adult stuttering. Jundishapur Sci Med J. 2020;18(6):559-70. DOI: 10.22118/jsmj.2020.199661.1806

21. Mozaffari A. The effectiveness of schema therapy on the level of stuttering in adults aged 25 to 35 years. 17th Iranian Speech Therapy Conference, Tehran, Iran; 2019. [Persian]

22. Young JE, Klosko JS, Weishaar ME. Schema therapy: a practitioner's guide. New York: Guilford Press; 2006.

23. Young JE, Klosko JS, Weishaar ME. Schema therapy: a practical guide. Trans: Hamidpoor $\mathrm{H}$, Andoz Z. Tehran: Arjmand; 2014. [Persian]

24. Orue I, Calvete E, Padilla P. Brooding rumination as a mediator in the relation between early maladaptive schemas and symptoms of depression and social anxiety in adolescents. $J$ Adolesc. 2014;37(8):1281-91. PMID: 25296399 DOI: 10.1016/j.adolescence.2014.09.004

25. Renner F, Robert D, Arnoud A, Frenk P, Marcus JH. Exploring mechanisms of change in schema therapy for chronic depression. J Behav Ther Exp Psychiatry. 2018; 58:97-105. PMID: 29035800 DOI: 10.1016/j.jbtep. 2017.10.002

26. Doomen I. The effectiveness of schema focused drama therapy for cluster C personality disorders: an exploratory study. Art Psychother. 2018;61:66-76. DOI: 10.1016/j.aip.2017.12.002

27. Riley GD. A stuttering severity instrument for children and adults. J Speech Hear Disord. 2009;37(3):314-322. PMID: 5057250 DOI: 10.1044 /jshd.3703.314

28. Sharifi HP. Principles of psychometrics and psychoanalysis. Tehran: Roshd Press; 2009. [Persian]

29. Gross JJ, John OP. Individual differences in two emotion regulation processes: implications for affect, relationships, and well-being. J Pers Soc Psychol. 2003;85(2):348-62. PMID: 12916575 DOI: 10.1037/0022-3514.85.2.348

30. Ahmadi SA, Kanaan Azar H, Nagahisarchoghaei M, Nagahi M. Relationship between emotional intelligence and psychological well being. Int J Res Organ Behav Hum Resour Manag. 2014;2(1):123.

31. Andami Khoshk A. The mediating role of resilience in the relationship between cognitive emotion regulation and tolerance for life satisfaction. [Master Thesis]. Tehran: Allameh Tabatabai University; 2013. [Persian]

32. Jashnpour M. The relationship between emotion regulation problems, tolerance of distress and inefficient attitudes with addiction to physical and motor disabilities in kermanshah. [Master Thesis]. Kermanshah: Razi University; 2017. [Persian]

33. Mohammadi H, Sepehri SZ, Asghari EM. The effectiveness of group emotional schema therapy on reducing psychological distress and the difficulty of regulating the 
excitement of divorced women. J Thoug Behav Clin Psychol. 2019;14(51):27-36. [Persian]

34. Bidari F, Haji Alizadeh K. The effectiveness of schema therapy on emotional cognitive strategies, tolerance for anxiety and mood swings in patients with borderline personality disorder. J Psychol Stud. 2019;15(2):165-80.

35. Farazi M, Tehrani LG, Koolaee AK, Shemshadi H, Rahgozar M. Effectiveness of integrated cognitive - speech approaches to the treatment of adult stuttering. Speech Lang Pathol. 2015;1(2):8-18. [Persian]

36. Rezaei M, Ghazanfari F, Kazemi R. Effectiveness of emotional schema therapy on the severity of depression and mental rumination in people with major depression. J Clin Psychol. 2016;24(1):45-58. [Persian]

37. Abbasabadi SS, Khalatbari J. The Effectiveness of schema therapy on life expectancy, emotion regulation and valuable feeling of patients with female sexual identity disorder. 2nd International Conference on New Research in Educational Sciences and Psychology and Social Studies in Iran, Tehran, Iran; 2016. [Persian]

38. Haghgu S, Babaei N. The effectiveness of schema therapy on intellectual rumination in children with cancer at Kermanshah Cancer Center. The First National Conference on Modern Research in Psychology, Counseling and Educational Sciences, Tehran, Iran; 2016. [Persian]

39. Liu TW, Ng GYF, Ng SS. Effectiveness of a combination of cognitive behavioral therapy and task-oriented balance training in reducing the fear of falling in patients with chronic stroke: study protocol for a randomized controlled trial. Trials. 2018;19(1):168. PMID: 29514677 DOI: 10.1186/s13063-018-2549-Z

40. Young JE. Cognitive therapy for personality disorders: a schema-focused approach. Washington, DC: Professional Resource Press/Professional Resource Exchange; 1999.

41. Wingate ME. Sound and pattern in "artificial" fluency. $J$ Speech Hear Res. 1969;12(4):677-86. PMID: 5385718 DOI: 10.1044/jshr.1204.677

42. Blomgren M, Roy Callister T, Merrill RM. Intensive stuttering modification therapy: a multidimensional assessment of treatment outcomes. J Speech Lang Hear Res. 2005;48(3):509-23. PMID: 16197269 DOI: 10.1044/10924388(2005/035)

43. Manning WH, DiLollo A. Clinical decision making in fluency disorders. Chicago: Plural Publishing; 2017.

44. Menzies RG, Onslow M, Packman A. Cognitive behavior therapy for adults \& children who stutter: a workshop for speech pathologists. Sydney, Australia: The University of Sydney; 2011.

45. Webster RL. The precision fluency shaping program: speech reconstruction for stutterers. Roanoke, VA: Communications Development Corporation; 1975.

46. Ward D. Stuttering and cluttering: frameworks for understanding treatment. New York: Psychology Press; 2006.

47. St Clare T, Menzies RG, Onslow M, Packman A, Thompson $\mathrm{R}$, Block S. Unhelpful thoughts and beliefs linked to social anxiety in stuttering: development of a measure. Int J Lang Commun Disord. 2009;44(3):338-51. PMID: 18821110 DOI: $\underline{10.1080 / 13682820802067529}$

48. Guitar B, McCauley RJ. Treatment of stuttering: Established and emerging interventions. Philadelphia: Lippincott Williams \& Wilkins; 2010. P. 188-214.

49. Breitenfeldt DH, Lorenz DR. Successful stuttering management program (SSMP): for adolescent and adult stutterers. Maryland: American Speech-Language-Hearing Association; 1990. P. 84-8.

50. Erfan A, Ali Noorbala A, Karbasi Amel S, Mohammadi A, Adibi P. The effectiveness of emotional schema therapy on the emotional schemas and emotional regulation in irritable bowel syndrome: single subject design. Adv Biomed Res. 2018;7(72):113-6. PMID: 29862221 DOI: 10.4103/abr. abr $113 \quad 16$

51. Shokhmgar Z. Effectiveness of Schema therapy on reducing mental health problems due to crossover relationships in couples. Nasim Health. 2016;51(17):1-7.

52. Sangani A, Dasht Bozorgi Z. The effectiveness of schema therapy on general health, ruminating and social loneliness of divorce women. J Psychol Achievem. 2018;25(2):201-16. DOI: 10.22055/PSY.2019.24944.2008

53. Fattahi AA, Dehghani A. The effectiveness of schema therapy on emotional regulation, self-efficacy and temptation in men who are members of the Association of Anonymous Addicts. Res Addict. 2018;12(48):187-204.

54. Dworsky CK, Pargament KI, Wong S, Exline JJ. Suppressing spiritual struggles: the role of experiential avoidance in mental health. J Contex Behav Sci. 2016;5(4):258-65. DOI: 10.1016/j.jcbs.2016.10.002

55. Thompson RA. Emotion regulation: A theme in search of definition. Monographs of the society for research in child development. Chicago: University of Chicago Press; 1994. P. 25-52.

56. Garnefski N, Kraaij V, van Etten M. Specificity of relations between adolescents cognitive emotion regulation strategies and internalizing and externalizing psychopathology. $J$ Adolesc. 2005;28(5):619-31. PMID: 16203199 DOI: 10.1016/j.adolescence.2004.12.009

57. de Lijster JM, Dieleman GC, Utens EM, van der Ende J, Alexander TM, Boon A, et al. Online attention bias modification in combination with cognitive-behavioural therapy for children and adolescents with anxiety disorders: a randomised controlled trial. Behav Change. 2019;36(4):20015. DOI: $10.1017 / \mathrm{bec} .2019 .8$

58. Pirnia B, Akhondi M, Pirnia K, Malekanmehr P, Farzaneh S, Deilam K, Zahiroddin A. A single-case experimental design to study the combination of cognitive-behavioral therapy and pharmacotherapy for smoking cessation. Crescen J Med Biol Sci. 2019;6(1):136-9.

59. Chung YH, Chang HH, Lu CW, Huang KC, Guo FR. Addition of one session with a specialist counselor did not increase efficacy of a family physician-led smoking cessation program. J Int Med Res. 2018;46(9):3809-18. PMID: 29896996 DOI: $10.1177 / 0300060518780151$

60. Berking M, Schwarz J. Affect regulation training. Handbook of emotion regulation. Berlin, Germany: Springer; 2014. P. 529-47. 